\title{
Prolyl Oligopeptidase Regulates Dopamine Transporter Phosphorylation in the Nigrostriatal Pathway of Mouse
}

\author{
Julku, Ulrika $\mathrm{H}$.
}

2018-01

Julku , U H, Panhelainen , A E , Tiilikainen , S E , Svarcbahs , R , Tammimäki , A E , Piepponen , T P , Savolainen , M H \& Myöhänen , T T 2018 , ' Prolyl Oligopeptidase

Regulates Dopamine Transporter Phosphorylation in the Nigrostriatal Pathway of Mouse ' , Molecular Neurobiology , vol. 55 , no. 1 , pp. 470-482 . https://doi.org/10.1007/s12035-016-0339-8

http://hdl.handle.net/10138/234334

https://doi.org/10.1007/s12035-016-0339-8

cc_by

acceptedVersion

Downloaded from Helda, University of Helsinki institutional repository.

This is an electronic reprint of the original article.

This reprint may differ from the original in pagination and typographic detail.

Please cite the original version. 


\section{Prolyl oligopeptidase regulates dopamine transporter phosphorylation}

in the nigrostriatal pathway of mouse

Ulrika H Julku ${ }^{1}$, Anne E Panhelainen ${ }^{2}$, Saija E Tiilikainen ${ }^{1}$, Reinis Svarcbahs ${ }^{1}$, Anne E Tammimäki ${ }^{1}$, T Petteri Piepponen ${ }^{1}$, Mari H Savolainen ${ }^{1}$, Timo T Myöhänen ${ }^{1}$

${ }^{1}$ University of Helsinki, Division of Pharmacology and Pharmacotherapy, Viikinkaari 5E, P.O. Box 56, 00014 University of Helsinki, Finland

${ }^{2}$ University of Helsinki, Institute of Biotechnology, Viikinkaari 5D, P.O. Box 56, 00014 University of Helsinki, Finland

Corresponding author: Timo T Myöhänen

timo.myohanen@helsinki.fi, Tel: +358-50-4480769

Acknowledgements: This work was supported by grants from the Academy of Finland (267788 and 2737991), University of Helsinki research grants, Jane and Aatos Erkko Foundation and from the Sigrid Juselius Foundation to TTM. Authors would like to thank Liisa Lappalainen and Susanna Norrbacka for excellent technical assistance.

Conflict of Interest: The authors declare no competing financial interests.

Keywords: prolyl oligopeptidase, PREP, dopamine, dopamine transporter, DAT, microdialysis 


\begin{abstract}
Alpha-synuclein is the main component of Lewy bodies, a histopathological finding of Parkinson's disease. Prolyl oligopeptidase (PREP) is a serine protease that binds to $\alpha$-synuclein and accelerates its aggregation in vitro. PREP enzyme inhibitors have been shown to block the $\alpha$-synuclein aggregation process in vitro and in cellular models, and also to enhance the clearance of $\alpha$-synuclein aggregates in transgenic mouse models. Moreover, PREP inhibitors have induced alterations in dopamine and metabolite levels, and dopamine transporter immunoreactivity in the nigrostriatal tissue. In this study, we characterized the role of PREP in the nigrostriatal dopaminergic and GABAergic systems of wild-type C57Bl/6 and PREP knock-out mice, and the effects of PREP overexpression on these systems. Extracellular concentration of dopamine and protein levels of phosphorylated dopamine transporter were increased and dopamine reuptake was decreased in the striatum of PREP knock-out mice, suggesting increased internalization of dopamine transporter from the presynaptic membrane. Furthermore, PREP overexpression increased the level of dopamine transporters in the nigrostriatal tissue but decreased phosphorylated dopamine transporters in the striatum in wildtype mice. Our results suggest that PREP regulates the function of dopamine transporter, possibly by controlling the phosphorylation and transport of dopamine transporter into the striatum or synaptic membrane.
\end{abstract}




\section{Introduction}

Prolyl oligopeptidase (PREP) is a highly conserved serine protease that hydrolyses prolinecontaining peptides shorter than 30 amino acids at least in vitro and also has non-hydrolytic functions [1,2]. In vitro, PREP cleaves many peptide hormones such as substance P, thyrotropin-releasing hormone, arginine-vasopressin, bradykinin, and neurotensin [1]. Many of these neuropeptides are related to Parkinson's disease (PD), Alzheimer's disease (AD) and other neurodegenerative diseases, and alterations in the PREP enzyme activity has been observed in the brain tissue of PD, AD, Lewy body dementia and Huntington's disease patients [3]. However, the role of PREP in neuropeptide cleavage in vivo, and the physiological importance of PREP have remained unclear [4-6].

PREP is widely distributed in different tissues in mammalian body but the highest activity has been measured in the brain. PREP localizes in GABAergic and cholinergic interneurons of the thalamus and cortex, as well as in the GABAergic neurons of the nigrostriatal tract and also, in lesser extent, in dopaminergic (DAergic) neurons [7-9]. PREP is mainly found in the cell cytosol but it can also be localized in the nucleus and bound to the membranes $[1,10]$. Moreover, PREP has been shown to co-localize with $\alpha$-synuclein (aSyn), which is the main component of the Lewy bodies of PD, and tau aggregates and beta-amyloid plaques of $\mathrm{AD}$ in the post mortem brain samples [11]. Earlier, it has been shown that PREP directly binds to aSyn and accelerates its aggregation in cellular models $[12,13]$. A potent and specific PREP inhibitor, KYP-2047,was able block the aggregation of aSyn and enhance the clearance of aSyn aggregates in both aSyn overexpressing cell lines and in aSyn transgenic mice [12]. KYP-2047 also increased the concentrations of dopamine (DA) and its metabolites and decreased DA transporter (DAT) immunoreactivity in the striatal tissue in wild-type mice and in aSyn transgenic mice, suggesting that PREP might have a role in regulating the nigrostriatal DAergic system [14]. Moreover, in the study by Jalkanen et al. [15] two PREP inhibitors, KYP-2047 
and JTP-4819, decreased extracellular DA levels in the rat striatum. Otherwise, the role of PREP in the nigrostriatal neurotransmitter systems has not been extensively studied.

Although the concentration of extracellular DA is predominantly regulated by diffusion, the kinetics and the volume of extrasynaptic DA is mainly regulated by DAT [16]. DAT function is regulated with several different mechanisms but the main regulator of internalization of DAT is protein kinase $\mathrm{C}$ (PKC) mediated phosphorylation [17-19]. Changes in DAT function has been connected to PD and other DA related diseases, and altered levels of DAT markers have been found in the brain of PD patients [20]. Balance in DAT levels in synaptic cleft is crucial, since increased DAT on cellular membrane can lead to the accelerated DA uptake, which in turn leads to oxidative stress, terminal damage and DA-induced cellular apoptosis [21,22]. aSyn binds to DAT and regulates its localization and function by recruiting and stabilizing the transporter on plasma membrane [22-24]. aSyn aggregation, the key player in cellular toxicity in PD, may cause elevated striatal extracellular levels of DA observed in the aSyn overexpressing mice [25]. Furthermore, aSyn aggregation has effect on DA packing and DAT trafficking $[26,27]$. However, this has been mostly studied in vitro, whereas mechanisms in vivo are poorly understood although they might be pivotal in the pathophysiology of PD and other neurodegenerative diseases [28]. Previous findings indicate that the regulation of DAergic system, DAT function and aSyn aggregation by modulating PREP functions might be a potential drug target in synucleinopathies and in other neurodegenerative diseases [14]. However, the physiological role of PREP protein in the nigrostriatal GABAergic and DAergic systems is still unclear, and needs to be clarified to further support development of the PREP inhibitors as drug therapy for PD. In this study, we have characterized the role of PREP in the nigrostriatal DAergic and GABAergic systems and its effect on DAT function by using PREP inhibitors, PREP knock-out mice and local PREP overexpression. Our results revealed that PREP regulates the DA level and uptake by affecting DAT trafficking in DAergic cells. 


\section{Materials and methods}

Reagents

The reagents were purchased from Sigma-Aldrich (MO, USA) if not otherwise specified. Ethanol was purchased from Altia (Finland). The PREP inhibitor, KYP-2047 (4phenylbutanoyl-1-prolyl-2(S)-cyanopyrrolidine), was synthesized in the School of Pharmacy, University of Eastern Finland, as previously described by Jarho et al [29]. KYP-2047 has been extensively characterized and the pharmacological and pharmacokinetic profile indicates that it is highly selective, potent, and crosses the blood-brain barrier both in rats and mice $[12,14$, 15, 30-32]. Adeno associated virus vectors (AAVs), AAV1-EF1 $\alpha$-hPREP (AAV-PREP) and AAV1-EF1 $\alpha-$ eGFP (AAV-GFP), were obtained from National Institute of Drug Abuse (Dr. Brandon Harvey, Intramural Research Program, Baltimore MD, USA). Plasmid construction was performed as described by Savolainen et al [14].

\section{Animals}

Male C57BL/6J mice (Wt) (7-9 weeks old; Envigo, The Netherlands) and PREP gene knock out mice (PREP-KO) in C57BL/6JRccHsd genetic background (5-10 back crossings) were used in this study $[33,34]$. Deletion of exon 3 of the PREP gene was done as described by Di Daniel et al [34]. Mice were housed under standard laboratory conditions (12 h light/dark cycle; room temperature $23 \pm 2{ }^{\circ} \mathrm{C}$; relative humidity: $50 \pm 15 \%$ ) in individually ventilated cages (Mouse IVC Green Line, Techniplast, Italy) with bedding (Aspen chips 5 x 5 x $1 \mathrm{~mm}, 4 \mathrm{HP}$, Tapvei, Estonia), nesting material (Aspen strips, PM90L, Tapvei), and aspen brick (100 x 20 x $20 \mathrm{~mm}$, Tapvei). Mice had access to chow food (Teklad 2016, Envigo, UK) and filtered and irradiated water ad libitum. After surgical procedures, animals were individually housed for the durations of the experiment. The experiments were carried out according to the European 
Communities Council Directive 86/609/EEC and were approved by the Finnish National Animal Experiment Board.

Surgical procedures

Mice were anesthetized with isoflurane (4\% induction, 1.5-2.0\% maintenance; Attane vet 1000 mg/g, Piramal Healthcare, UK) and the recombinant AAV1 viral vectors were injected above the substantia nigra $(\mathrm{SN})$ in a stereotaxic operation. To target the $\mathrm{SN}$, viral vectors were given as a single injection (volume $1 \mu \mathrm{L}$, rate $0.2 \mu \mathrm{L} / \mathrm{min}$ ) into the left hemisphere, $3.1 \mathrm{~mm}$ anterior and $1.2 \mathrm{~mm}$ lateral to bregma, and $4.2 \mathrm{~mm}$ below the dura (stereotaxic coordinates according to Paxinos and Frankin [35]). Buprenorphine (0.1 mg/kg s.c.; Temgesic 0,3 mg/mL, Reckitt Benckiser Healthcare, UK) was given before the operation, $12 \mathrm{~h}$ and $24 \mathrm{~h}$ after the surgery to relieve post-operative pain. Guide cannula for microdialysis was inserted into the left striatum at $0.6 \mathrm{~mm}$ anterior and $1.8 \mathrm{~mm}$ lateral, and $2.7 \mathrm{~mm}$ below the dura. The cannula was fastened to the skull with dental cement (Aqualox, Voco, Germany) and two stainless steel screws (1.2 x 3 mm, DIN84, Helsingin Ruuvihankinta, Finland).

Characterization of viral vectors

To characterize the distribution and function of viral vectors, AAV1-EF1 $\alpha$-eGFP or AAV1EF1 $\alpha$-hPREP were injected unilaterally above the SN to Wt mice and the expression and distribution was examined by immunohistochemistry 2 and 4 weeks post-injection. PREP enzyme activity in the striatal tissue was measured 4 weeks post-injection. Detailed description of PREP enzyme activity assay and immunohistochemistry can be found in the Supplementary material (Fig. S1-2). 
Conventional microdialysis

Microdialysis was performed 5 weeks after the viral vector injections as described earlier [36]. A microdialysis probe (1-mm cuprophan membrane, o.d. $0.2 \mathrm{~mm}, 6 \mathrm{kDa}$ cut-off; AT4.9.1.Cu, AgnTho's, Sweden) was inserted into the guide cannula 2 hours before the experiment and the probe was perfused with a modified Ringer solution $\left(147 \mathrm{mM} \mathrm{NaCl}, 1.2 \mathrm{mM} \mathrm{CaCl}_{2}, 2.7 \mathrm{mM}\right.$ $\mathrm{KCl}, 1.0 \mathrm{mM} \mathrm{MgCl}$, and $0.04 \mathrm{mM}$ ascorbic acid) at the flow rate of $2.0 \mu \mathrm{L} / \mathrm{min}$. Five baseline samples were collected $(20 \mathrm{~min} / 40 \mu \mathrm{L} / \mathrm{sample})$ after the stabilization period. After the collection of baseline samples, the probe was perfused $2 \times 20$ min with $10 \mu \mathrm{M}$ and $30 \mu \mathrm{M}$ damphetaminesulphate with $2 \times 20$ min recovery time between the concentrations. The mice were euthanized right after the microdialysis experiment by cervical dislocation followed by decapitation. The brains were removed and rapidly frozen in isopentane on dry ice. The concentrations of dopamine (DA), its metabolites, dihydroxyphenylacetic acid (DOPAC) and homovanillic acid (HVA), and 5-hydroxyindoleacetic acid (5-HIAA) as well as gammaaminobutyric acid (GABA) in dialysates were measured using slightly modified versions of the HPLC methods that have been described earlier [37,36]. Detailed description of the HPLC systems can be found in the Supplementary material.

Similar microdialysis experiment was performed with PREP inhibitor administration in Wt mice. After collecting baseline samples for $4 \times 20$ min, KYP-2047 or vehicle was injected intraperitoneally and, thereafter, $15 \times 20$ min samples were collected. A repeated experiment was carried out with the same mice after a 5-day treatment of KYP-2047 or vehicle. In the repeated experiment, 9x20 min samples were collected after the stabilization period. Amphetamine-induced DA release was measured in another set of mice. The mice received an injection of KYP-2047 or vehicle after the collection of 4x20 min baseline samples and 
administration of amphetamine via probe (as described above) was started $3 \times 20$ min after the injection.

No-net-flux microdialysis

No-net-flux microdialysis was performed with PREP-KO mice and Wt littermates. A microdialysis probe (1-mm cuprophan membrane, o.d. $0.2 \mathrm{~mm}, 6 \mathrm{kDa}$ cut-off; AT4.9.1.Cu, AgnTho's, Sweden) was inserted into the guide cannula 2 hours before the experiment and the probe was perfused with a modified Ringer solution $(147 \mathrm{mM} \mathrm{NaCl}, 1.2 \mathrm{mM} \mathrm{CaCl} 2,2.7 \mathrm{mM}$ $\mathrm{KCl}, 1.0 \mathrm{mM} \mathrm{MgCl}$, and $0.04 \mathrm{mM}$ ascorbic acid) at the flow rate of $0.6 \mu \mathrm{L} / \mathrm{min}$. Four concentrations of DA in Ringer solution $\left(\mathrm{C}_{\mathrm{in}} ; 0,2,10\right.$ and $\left.20 \mathrm{nM}\right)$ were perfused through the probes in a random order, and $3 \times 30$ min samples were collected at each $\mathrm{C}_{\mathrm{in}}$ for HPLC analysis.

Linear equation was constructed for each animal by plotting the net flux of DA through the probe $\left(\mathrm{DA}_{\text {in }}-\mathrm{DA}_{\text {out }}\right)$ against $\mathrm{DA}_{\text {in }}$, where $\mathrm{DA}_{\text {out }}$ is the dialysate $\mathrm{DA}$ concentration acquired during the perfusion and $\mathrm{DA}_{\mathrm{in}}$ is the $\mathrm{DA}$ concentration of the perfusion fluid. Based on this equation, the extracellular DA level (DA $\mathrm{Dext})$ and the in vivo extraction fraction $\left(\mathrm{E}_{\mathrm{d}}\right)$ was calculated as described by Parsons and Justice [38]. The DA $\mathrm{A}_{\mathrm{ext}}$ value stands for the perfusion fluid DA concentration at which there is no-net-flux of DA through the probe $\left(\mathrm{DA}_{\text {in }}-\mathrm{DA}_{\text {out }}=\right.$ 0). $E_{d}$, on the other hand, has been shown to describe combined DAT, NET and uptake2 functions [39-42].

Tissue HPLC analysis

Striatal tissue samples were punched below the corpus callosum $+0.74 \mathrm{~mm}$ from the bregma to $2 \mathrm{~mm}$ depth by using sample corer (i.d. of $2 \mathrm{~mm}$ ) with a plunger (Stoelting Co, USA) on a cryostat (Leica CM3050) and the samples from the SN were punched from a brain slice (thickness 1-1.5 mm) - $2.8 \mathrm{~mm}$ from the bregma by using sample corer (i.d. of $1 \mathrm{~mm}$ ) with a 
plunger (Stoelting Co). Tissue processing and HPLC analysis of the concentrations of DA, its metabolites DOPAC and HVA, and 5-HIAA in the tissue were performed as described earlier [43]. Detailed description of the HPLC equipment can be found in the Supplementary material. The tissue concentrations of GABA and glutamate were analyzed with HPLC equipped with a fluorescence detector. Detailed description of the HPLC system can be found in the Supplementary material. Concentrations are calculated as nanograms per milligram of brain tissue.

\section{Western blotting}

Frozen tissue was homogenized with an ultrasound sonicator (GM35-400, Rinco Ultrasonic, Switzerland) in 5 volumes of ice cold modified RIPA buffer (50 mM Tris $\mathrm{HCl}$ pH 7.4, $1 \%$ NP40, $0.25 \%$ sodium deoxycholate, $150 \mathrm{mM} \mathrm{NaCl}$ ) containing Halt Phosphatase Inhibitor (Product\# 87786, Thermo Fisher Scientific, IL, USA) and Halt Protease Inhibitor cocktail (Product\# 78430, Thermo Fisher Scientific). After centrifuging at $16,000 \mathrm{~g}$ and $4^{\circ} \mathrm{C}$ for $15 \mathrm{~min}$, the supernatants were collected. Protein concentration was measured by the BCA method (Thermo Fisher Scientific). For SDS-PAGE, $30 \mu \mathrm{g}$ of protein was loaded onto a 4-20\% MiniPROTEAN TGX precast gel (Product \# 4561094, Bio-Rad, CA, USA). Gel was transferred to nitrocellulose membrane (Trans-blot Turbo, Product\# 1704158, Bio-Rad) by using Trans-blot Turbo Transfer System (Bio-Rad). The membranes were blocked by 5\% skim milk. Western blots for DAT, tyrosine hydroxylase (TH) and beta-actin were done with SNAP i.d. 2.0 protein detection system (Merck Millipore, MA, USA), except phospho (T53)-DAT that was done by incubating the membrane with primary antibody overnight at $+4{ }^{\circ} \mathrm{C}$ and thereafter with secondary antibody for $2 \mathrm{~h}$ at room temperature. Following primary antibodies and dilutions were used: DAT, rabbit anti-DAT (\#PA1-4656, Thermo Fisher Scientific, dilution 1:1000 in $0.5 \%$ skim milk in $0.1 \%$ Tween-20 in tris-buffered saline (TTBS)); phospho (T53)-DAT 
(pDAT), rabbit anti-pDAT (\#ab183486, AbCam, UK, dilution 1:500 in 5\% skim milk in 0.05\% TTBS); TH, rabbit anti-TH (\#ab153, Merck Millipore, dilution 1:2000 in 0.5\% skim milk in 0.1\% TTBS); beta-actin, rabbit anti-beta-actin (\#4967S, Signalling Technology, MA, USA, dilution 1:1000 in $0.5 \%$ skim milk in $0.1 \%$ TTBS). Goat anti-rabbit HRP was used for secondary antibody for all the primary antibodies (\#31460, Thermo Fisher Scientific, dilution 1:2000 in $0.5 \%$ skim milk in $0.1 \%$ TTBS). The images were captured with LI-COR C-digit chemiluminescence scanner (LI-COR, Germany). Three independent WB experiments were performed.

Optical density (OD) values of the WB images were analysed using ImageJ software (NIH, MD, USA). The OD values were normalized to the loading control (beta-actin) OD's.

Fast-scan cyclic voltammetry

Dopamine release was evoked on acute striatal slices of male mice (5-6 months of age) with electrical stimulations and measured with a carbon fiber electrode calibrated with known dopamine concentrations. The signal was amplified with Axopatch 200B amplifier (Molecular Devices LLC, CA, USA), digitized (ITC-18 board; Instru-Tech, NY, USA) and analyzed with a computer routine in IGOR Pro (WaveMetrics, OR, USA) as earlier described [44]. Detailed description of fast-scan cyclic voltammetry can be found in the Supplementary material.

PREP inhibitor treatments

Wt mice received either the PREP inhibitor KYP-2047 (5 mg/kg) or vehicle twice a day intraperitoneally (i.p.) for 5 days. KYP-2047 was diluted in 0.5\% dimethylsulfoxide (DMSO) in saline. Vehicle treatment groups received $0.5 \%$ DMSO in saline. 
Cylinder test

Cylinder test (cylinder height $15 \mathrm{~cm}$, diameter $12 \mathrm{~cm}$ ) was used to measure motor asymmetry in spontaneous forelimb use after the unilateral microinjections $[45,46]$. Baseline paw preference scores were acquired before the stereotaxic surgery, 2 weeks and 4 weeks postinjection. In brief, mouse was filmed for 5 minutes. If the number of the individual rearing episodes that resulted in the mouse touching cylinder wall was less than 10 , the mouse was excluded from the further analysis. Data was analyzed by a formula $\frac{\text { Contralateral }+0.5 * \text { Both }}{\text { Ipsilateral }+ \text { Contralateral }+ \text { Both }} * 100 ;$ where 'Both' paws were defined as touches where animal landed both of the forepaws simultaneously on the cylinder wall after the rearing. A noninjected control mouse should score around 50\% in this test. The animals were not allowed to habituate to the testing cylinder before the video recording. The baseline level was set to 100 $\%$; the results at 2 and 4 weeks were calculated as $\%$ of the baseline.

\section{Locomotor activity test}

The spontaneous locomotor activity of the AAV-transfected animals was measured before the AAV-injections and 4 weeks after the injections and that of the PREP inhibitor-treated animals was measured before the treatment and after a 5-day treatment with KYP-2047. At the beginning of the lights-on period, the animals were placed in transparent cages $(25 \mathrm{~cm} \mathrm{x} 25 \mathrm{~cm}$ $\mathrm{x} 15 \mathrm{~cm}$, with food pellets and a water burette) with the activity monitor measuring infrared beam interruptions (MED Associates, GA, USA). The measurement was started immediately to record also the explorative behavior in a novel environment, and the data were collected at 15-min intervals for 20 hours. 
Statistical analysis

Statistical analysis was performed using either GraphPad Prism (version 6.02, GraphPad Software, Inc., CA, USA) or SPSS Statistics (Version 22.0.0.1 IBM Corporation, NY, USA) software. One- and two-way ANOVA with Bonferroni post-test and Student's t-test were used as statistical tests. Data is presented as mean \pm standard error of the mean (SEM). The results were considered to be statistically significant at $\mathrm{p}<0.05$.

\section{Results}

Increased dopaminergic activity in the striatum of PREP knock-out mice

The impact of absence of PREP in the nigrostriatal DAergic and GABAergic systems was examined in PREP-KO mice and their Wt littermates by striatal no-net-flux microdialysis to measure the extracellular baseline level of DA, by conventional microdialysis to study the amphetamine-induced DA release, and by tissue HPLC analysis to measure the concentration of neurotransmitters and their metabolites in the striatal and SN tissue. The striatal extracellular DA concentration was significantly increased in PREP-KO mice compared to Wt littermates in no-net-flux microdialysis study (Fig. 1a; $\mathrm{p}=0.036$, Student's t-test). The PREP-KO mice had approximately $80 \%$ higher concentration of extracellular DA in the striatum than their $\mathrm{Wt}$ littermates. Additionally, the PREP-KO mice showed more pronounced amphetamine-induced release of DA in the conventional microdialysis experiment (Fig. 2b, $10 \mu \mathrm{M}$ amphetamine $(\mathrm{AMPH})$, genotype effect: $\mathrm{F}_{1,37}=6.799, \mathrm{p}=0.013,30 \mu \mathrm{M}$ AMPH, genotype effect: $\mathrm{F}_{1,37}=$ 8.681, $\mathrm{p}=0.006$, repeated measures 2-way ANOVA). PREP-KO mice were also more active during the exploratory phase in the locomotor activity test (Fig. S3a in the Supplementary material, 0-60 min: $F_{1,22}=7.567, p=0.012$, repeated measures 2-way ANOVA). Tissue 
concentrations of DA, 5-HT, their metabolites, glutamate and GABA in the striatum and SN were similar in both genotypes (Fig. 3).

Altered DAT phosphorylation and function in the PREP knock-out mice

The levels of DA-related proteins DAT and TH in the striatal and SN tissue were studied by Western blotting, and DAT function was studied in acute striatal slices by fast-scan cyclic voltammetry. PREP-KO and Wt mice had similar concentration of DAT in the nigrostriatal tract (Fig. 4a-b) but the level of phosphorylated DAT was higher in the striatum of PREP-KO mice (Fig. 4c; $p=0.0338$, Student's t-test). In addition, TH level was increased in the SN tissue but not in the striatal tissue of PREP-KO mice (Fig. 4e-f; $p=0.0038$, Student's t-test). Several parameters representing the DA release and reuptake dynamics were calculated from the single pulse stimulation -evoked DA transients recorded with fast-scan cyclic voltammetry in acute striatal slices. The efficacy of DA reuptake by DAT can be estimated from the half width of the transients (the width of the transient at half maximum of the DA peak) as well as from the fall time and tau values of the exponential decays of the transients [47]. The half widths (Fig. $1 \mathrm{~d}, \mathrm{p}=0.0020$, Student's t-test) and values (Fig. 1e, $\mathrm{p}=0.028$, Student's t-test) of DA peaks were increased in the PREP-KO mice and there was a similar trend in the fall time (Fig 1f, $\mathrm{p}=$ 0.078, Student's t-test) suggesting that the DA reuptake was delayed. The amount of DA released by single pulses i.e. the peaks of the transients were slightly higher in PREP-KO mice but there was no statistically significant difference (Fig. 1c, $\mathrm{p}=0.356$, Student's t-test). The recovery of the DA terminals from the preceding exocytosis in paired-pulse stimulations and the amounts of DA released by burst stimulations were similar in the PREP-KO and Wt mice (Fig. S4a-b in the Supplementary material). In addition, in slice recordings, in the dorsal striatal area, the amphetamine-induced DAT reversal and DA release through DAT was unchanged (Fig. S4c-d in the Supplementary material). 
Overexpression of PREP elevates the striatal DAT in wild-type mice

The effect of PREP overexpression in the nigrostriatal tract was studied by the striatal microdialysis and tissue HPLC analysis, and the DA-related proteins DAT and TH were studied by Western blotting. The behavioral effects caused by the unilateral nigral PREP overexpression were studied by cylinder test and locomotor activity test. The nigrostriatal overexpression of PREP by AAV-hPREP did not have an effect on the extracellular baseline concentration of DA (Fig. 2a) and its metabolites (Fig. 2c-d) or amphetamine-induced release of DA (Fig. 2b) but the baseline level of 5-HIAA (Fig.2e; $p=0.0048$, Student's t-test) and GABA (Fig. 2f; p = 0.047, Student's t-test) were elevated. Tissue concentrations of DA, 5-HT, their metabolites, glutamate and GABA in the striatum were unchanged (Fig. 3) but DA in the SN was elevated (Fig. 3h). Overexpression of PREP also increased the protein level of DAT in the striatum (Fig. 5a; $p=0.027$, Student's t-test) and in the SN (Fig. 5b; $p=0.033$, Student's t-test) measured by Western blotting. Moreover, phosphorylated DAT was decreased in the striatum (Fig. 5c; p = 0.0281, Student's t-test) but not in the SN (Fig. 5d). The amount of TH was unchanged both in the striatum and SN (Fig. 5e-f). Unilateral PREP overexpression did not have an effect on the locomotor activity (Fig. S3b in the Supplementary material) but AAVGFP decreased the use of the contralateral paw in the cylinder test (Fig. S5 in the Supplementary material, baseline vs. 4 weeks, $F_{2,32}=3.547, * p=0.044,1$-way ANOVA, Bonferroni post-test).

Restoring PREP protein to the substantia nigra of PREP knock-out mice increases the striatal dopamine

PREP function was restored to PREP-KO mice by a nigral injection of AAV-hPREP, and the nigrostriatal DAergic and GABAergic systems were studied 5 weeks post-injection by conventional microdialysis and tissue HPLC analysis. Behavior was studied with cylinder test 
and locomotor activity test. Restoring the PREP function to the PREP-KO mice did not have an effect on the extracellular concentration of DA, its metabolites or 5-HIAA (Fig. 2a, 2c-f) but the striatal tissue concentration of DA was increased (Fig. 3a; $p=0.016$, Student's t-test). Levels of DA-related proteins DAT, pDAT and TH were not changed (Fig. S6 in the Supplementary material). Use of contralateral paw was increased in the mice that received an AAV-hPREP injection (Fig. S5 in the Supplementary material, baseline vs. 4 weeks, $F_{2,14}=$ 4.994, $\mathrm{p}=0.029,1$-way ANOVA, Bonferroni post-test) but remained at the baseline level in the AAV-GFP group. Restoring the PREP function did not have an effect on the locomotor activity (Fig. S3c in the Supplementary material)

PREP inhibition induced alteration on the metabolites of dopamine in wild-type mice

PREP inhibition elevated concentration of DA in the striatum of A30P point-mutated transgenic mice but not in the Wt mice in a previous study [14]. In addition, immunoreactivity of DAT was increased in both Wt and transgenic mice. To study these observations further, we examined the effect of acute and long-term PREP inhibition on the nigrostriatal DAergic and GABAergic system by microdialysis, tissue HPLC analysis and Western blotting. The single dose of PREP inhibitor, KYP-2047, did not have an effect on the extracellular baseline levels of DA, its metabolites, GABA and 5-HIAA (Fig. S7 in the Supplementary material) or amphetamine-induced release of DA (Fig. S8 in the Supplementary material) in the microdialysis study but the 5-day treatment by KYP-2047 elevated HVA level (Fig. S7F in the Supplementary material, $\mathrm{p}=0.0359$, Student's t-test) and there was a similar trend in DOPAC (Fig. S7d in the Supplementary material, $\mathrm{p}=0.0774$, Student's t-test). Tissue concentration of DA and 5-HT, their metabolites, GABA, glutamate, DAT, pDAT and TH in the striatum and in the SN remained unchanged (Fig. S9 and Fig. S10 in the Supplementary material), and the 
PREP inhibition did not have an effect on the locomotor activity either (Fig. S3e-f in the Supplementary material).

\section{Discussion}

In this study, we comprehensively studied the absence, restoration and overexpression of PREP protein on the nigrostriatal pathway to reveal the role of PREP in the striatal and the nigral DAergic and GABAergic system. In addition, the effect of acute and 5-day PREP inhibitor treatment on the nigrostriatal neurotransmitter systems was studied. The most significant finding was that the absence of PREP protein in the knock-out mice caused elevated extracellular DA levels and impaired DAT function in the striatum, suggesting a role for PREP in DAT internalization. To our knowledge, this is the first study where the role of PREP on DAT function has been observed, and the overall importance of PREP protein for neurotransmitter systems of the nigrostriatal pathway has been characterized.

In earlier studies, PREP expression has been detected in the nigrostriatal GABAergic neurons and to some extent in DAergic neurons, and administration of PREP inhibitors has decreased the extracellular DA in the rat striatum [15], and chronic PREP inhibitor treatment has decreased DAT-immunoreactivity in the mouse striatal tissue [14]. However, the physiological role of PREP protein in the nigrostriatal neurotransmission has remained unclear. In this study, we found that the PREP-KO mice had higher concentrations of pDAT in the striatum. This indicates that PREP-KO mice have more internalized DAT and less DAT on the presynaptic membrane as phosphorylation is the main regulator of DAT internalization [17,19]. As DAT can transport DA only when located on the cellular membrane, low concentrations of DAT on the membrane cause impaired reuptake of DA, which was seen in the current study as higher extracellular concentrations of DA in the no-net-flux microdialysis and as delayed reuptake of DA in the fast-scan cyclic voltammetry measurements. Elevated amphetamine-induced release 
of DA in the conventional microdialysis experiment also further supports the altered DAT function and DA reuptake in the PREP-KO mice. Amphetamine rapidly diminishes DAT function by phosphorylation of DAT via PKC or oxidative inactivation leading to a massive reduction of DA clearance in the extracellular space [48]. Reduced DAT function on the presynaptic membranes of PREP-KO mouse leads to reduced reuptake and increased extracellular DA that was seen in the microdialysis experiment. The high concentration of $\mathrm{TH}$ in the SN can also explain the higher amount of the extracellular DA in the PREP-KO mouse as TH is the rate limiting enzyme in DA synthesis [49].

Altered DAT function induced by absence or overexpression of PREP suggests that PREP has an important role in the nigrostriatal DAergic system regulating the phosphorylation and internalization of DAT. This was further supported by the overexpression studies, where we detected increased level of DAT in the nigrostriatal tract and reduced pDAT in the striatum, indicating that internalization of DAT is decreased and the level of DAT is elevated on the cellular membrane. Interestingly, there were no statistically significant changes in the extracellular or tissue concentration of DA in the striatum, indicating that the physiological amount of PREP in DAergic neurons is sufficient to regulate DAT trafficking effectively. However, PREP overexpression resulted in an increased levels of the extracellular GABA and HVA in the striatum, and elevated tissue DA levels in the SN. Since this is the first time when PREP has been connected to the DAT functions and trafficking, the mechanism behind this is not yet known. PREP has been connected to cellular microtubule network, and trafficking and secretion of proteins [10], which might link it to DAT trafficking and internalization. Other possibility is that PREP regulates the phosphorylation of DAT via PKC or Jun-kinases but both of these theories require further studies.

In addition, increased explorative behavior in locomotor activity test correlates with the elevated DAergic activity in the nigrostriatal tract of PREP-KO mice. Locomotor hyperactivity 
of the PREP-KO mice has also been found in an earlier study [33] and acute PREP inhibition has also resulted in increased explorative activity in rats [50], suggesting a role of PREP in DA-regulated locomotor activity.

Restoring PREP function did not have an effect on the extracellular level of neurotransmitters and their metabolites or DA related proteins indicating that the PREP-KO mice might have some compensating mechanisms regulating DAergic system. However, the tissue concentration of DA in the striatum was elevated which might indicate a normalized DA function and might explain the increased use of contralateral paw in the cylinder test. Intriguingly, AAV-GFP had a toxic effect on contralateral paw use in the Wt but not in PREPKO mice in the cylinder test, suggesting that the PREP-KO mice might have some neuroprotective mechanisms against the protein overexpression. One possible mechanism for this could be increased clearance of protein overload by cellular autophagy, as it has been shown PREP to be a negative regulator of PI3K class III autophagy [14].

PREP inhibition has been shown to increase the striatal tissue concentration of DA in aged A30P point-mutated transgenic mice but not in Wt mice [14] and to reduce extracellular DA after acute dosing in rats [15]. In this study, we found that the 5-day treatment with PREP inhibitor did not have an effect on the extracellular concentration of DA in either genotype but the level of DA metabolites was increased in the Wt mice. Tissue concentration of DA and 5HT, their metabolites, GABA, glutamate or DAT was not changed. In the previous study [14], the level of DA metabolites was increased in the striatal tissue. However, in that study the samples were collected 32 hours after the last injection of KYP-2047 whereas in this study the tissue samples were collected already 8 hours after the injections. The different time point might explain the difference in the results. Additionally, we used young mice in this study whereas mice aged 12 to 16 months were used in the previous study. In the earlier study, DAT immunoreactivity in striatum was increased after the chronic PREP inhibition but we did not 
find any differences in the DAT in a Western blot analysis despite that the PREP overexpression-induced the striatal DAT level. However, aging may cause the alteration in DAT function, which might explain the difference between young mice in this study and aged mice in the previous study [51-53]. Furthermore, we did not use long-term inhibition of PREP in the present study. In contrast to the study by Jalkanen et al [15], we did not find any changes in DA or metabolite levels following an acute PREP inhibitor injection but the dissimilarity may be explained by a different dose of KYP-2047 (5 mg/kg vs. $17 \mathrm{mg} / \mathrm{kg})$ and by the use of different species.

In conclusion, our results show that (1) the absence and the overexpression of PREP causes changes in phosphorylation of DAT, (2) the active site inhibitor KYP-2047 does not imitate the lack of PREP expression, (3) the hyperactivity of PREP-KO mice is due to increased DA action, and (4) the restoration of PREP function does not have effect on DAT indicating compensative mechanisms in PREP-KO mice. The results suggest that PREP protein has a remarkable role in the nigrostriatal DAergic system by regulating DAT trafficking or internalization.

\section{Funding}

This work was supported by grants from the Academy of Finland (267788 and 2737991), University of Helsinki research grants, Jane and Aatos Erkko Foundation and from the Sigrid Juselius Foundation to TT Myöhänen.

\section{Conflict of Interest}

The authors declare that they have no conflict of interest.

\section{References}

1. Myöhänen TT, García-Horsman JA, Tenorio-Laranga J, Männistö PT (2009) Issues about the physiological functions of prolyl oligopeptidase based on its 
discordant spatial association with substrates and inconsistencies among mRNA, protein levels, and enzymatic activity.J Histochem \& Cytochem 57:831-848

2. García-Horsman JA, Männistö PT, Venäläinen JI (2007) On the role of prolyl oligopeptidase in health and disease. Neuropept 41:1-24

3. Mantle D, Falkous G, Ishiura S, Blanchard PJ, Perry EK (1996) Comparison of proline endopeptidase activity in brain tissue from normal cases and cases with Alzheimer's disease, Lewy body dementia, Parkinson's disease and Huntington's disease. Clin Chim Acta 249:129-139

4. Männistö PT, Venäläinen J, Jalkanen A, García-Horsman JA (2007) Prolyl oligopeptidase: a potential target for the treatment of cognitive disorders. Drug News Perspect 20:293-305

5. Tenorio-Laranga J, Männistö PT, Storvik M, Van der Veken P, García-Horsman JA (2012) Four day inhibition of prolyl oligopeptidase causes significant changes in the peptidome of rat brain, liver and kidney. Biochimie 94:1849-1859

6. Jalkanen AJ, Savolainen K, Forsberg MM (2011) Inhibition of prolyl oligopeptidase by KYP-2047 fails to increase the extracellular neurotensin and substance P levels in rat striatum. Neurosci Lett 502:107-111

7. Myöhänen TT, Venäläinen JI, Garcia-Horsman JA, Piltonen M, Männistö PT (2008) Cellular and subcellular distribution of rat brain prolyl oligopeptidase and its association with specific neuronal neurotransmitters.J Comp Neurol 507:16941708

8. Myöhänen TT, Kääriäinen TM, Jalkanen AJ, Piltonen M, Männistö PT (2009) Localization of prolyl oligopeptidase in the thalamic and cortical projection neurons: A retrograde neurotracing study in the rat brain. Neurosci Lett 450:201205

9. Peltonen I, Myöhänen TT, Männistö PT (2012) Different Interactions of Prolyl Oligopeptidase and Neurotensin in Dopaminergic Function of the Rat Nigrostriatal and Mesolimbic Pathways. Neurochem Res 37:2033-2041

10. Schulz I, Zeitschel U, Rudolph T, Ruiz-Carrillo D, Rahfeld JU, Gerhartz B, Bigl V, Demuth HU, Roßner S (2005) Subcellular localization suggests novel functions for prolyl endopeptidase in protein secretion. J Neurochem 94:970-979

11. Hannula MJ, Myöhänen TT, Tenorio-Laranga J, Männistö PT, Garcia-Horsman JA (2013) Prolyl oligopeptidase colocalizes with $\alpha$-synuclein, $\beta$-amyloid, tau protein and astroglia in the post-mortem brain samples with Parkinson's and Alzheimer's diseases. Neurosci 242:140-150

12. Myöhänen TT, Hannula MJ, Van Elzen R, Gerard M, Van Der Veken P, GarcíaHorsman JA, Baekelandt V, Männistö PT, Lambeir AM (2012) A prolyl oligopeptidase inhibitor, KYP-2047, reduces $\alpha$-synuclein protein levels and aggregates in cellular and animal models of Parkinson's disease. Br J Pharmacol 166:1097-1113

13. Savolainen MH, Yan X, Myöhänen TT, Huttunen HJ (2015) Prolyl oligopeptidase enhances alpha-synuclein dimerization via direct protein-protein interaction. J Biol Chem 290:5117-5126

14. Savolainen MH, Richie CT, Harvey BK, Männistö PT, Maguire-Zeiss KA, Myöhänen TT (2014) The beneficial effect of a prolyl oligopeptidase inhibitor, 
KYP-2047, on alpha-synuclein clearance and autophagy in A30P transgenic mouse. Neurobiol Dis 68:1-15

15. Jalkanen AJ, Piepponen TP, Hakkarainen JJ, De Meester I, Lambeir A-M, Forsberg MM (2012) The effect of prolyl oligopeptidase inhibition on extracellular acetylcholine and dopamine levels in the rat striatum. Neurochem Int 60:301-309 16. Rice ME, Cragg SJ (2008) Dopamine spillover after quantal release: rethinking dopamine transmission in the nigrostriatal pathway. Brain Res Rev 58:303-313 17. Melikian HE, Buckley KM (1999) Membrane trafficking regulates the activity of the human dopamine transporter. J Neurosci 19:7699-7710

18. Vaughan RA, Huff RA, Uhl GR, Kuhar MJ (1997) Protein kinase C-mediated phosphorylation and functional regulation of dopamine transporters in striatal synaptosomes. J Biol Chem 272:15541-15546

19. Daniels GM, Amara SG (1999) Regulated trafficking of the human dopamine transporter clathrin-mediated internalization and lysosomal degradation in response to phorbol esters.J Biol Chem 274:35794-35801

20. Ishibashi K, Oda K, Ishiwata K, Ishii K (2014) Comparison of dopamine transporter decline in a patient with Parkinson's disease and normal aging effect. J Neurol Sci 339:207-209

21. Chen L, Ding Y, Cagniard B, Van Laar AD, Mortimer A, Chi W, Hastings TG, Kang UJ, Zhuang X (2008) Unregulated cytosolic dopamine causes neurodegeneration associated with oxidative stress in mice.J Neurosci 28:425-433

22. Lee FJ, Liu F, Pristupa ZB, Niznik HB (2001) Direct binding and functional coupling of $\alpha$-synuclein to the dopamine transporters accelerate dopamineinduced apoptosis. FASEB J 15:916-926

23. Butler B, Saha K, Rana T, Becker JP, Sambo D, Davari P, Goodwin JS, Khoshbouei H(2015) Dopamine Transporter Activity Is Modulated by $\alpha$-synuclein.J Biol Chem 290:29542-29554

24. Fountaine TM, Wade-Martins R (2007) RNA interference-mediated knockdown of $\alpha$-synuclein protects human dopaminergic neuroblastoma cells from MPP+toxicity and reduces dopamine transport. J Neurosci Res 85:351-363 25. Lam HA, Wu N, Cely I, Kelly RL, Hean S, Richter F, Magen I, Cepeda C, Ackerson LC, Walwyn W (2011) Elevated tonic extracellular dopamine concentration and altered dopamine modulation of synaptic activity precede dopamine loss in the striatum of mice overexpressing human $\alpha$-synuclein.J Neurosci Res 89:1091-1102 26. Abeliovich A, Schmitz Y, Fariñas I, Choi-Lundberg D, Ho W-H, Castillo PE, Shinsky N, Verdugo JMG, Armanini M, Ryan A (2000) Mice lacking $\alpha$-synuclein display functional deficits in the nigrostriatal dopamine system. Neuron 25:239252

27. Chadchankar H, Ihalainen J, Tanila H, Yavich L (2011) Decreased reuptake of dopamine in the dorsal striatum in the absence of alpha-synuclein. Brain Res 1382:37-44

28. German CL, Baladi MG, McFadden LM, Hanson GR, Fleckenstein AE (2015) Regulation of the Dopamine and Vesicular Monoamine Transporters: Pharmacological Targets and Implications for Disease. Pharmacol Rev 67:10051024. 
29. Jarho EM, Venäläinen JI, Huuskonen J, Christiaans JAM, Garcia-Horsman JA, Forsberg MM, Järvinen T, Gynther J, Männistö PT, Wallén EAA (2004) A cyclopent2-enecarbonyl group mimics proline at the P2 position of prolyl oligopeptidase inhibitors. J Medic Chem 47:5605-5607

30. Jalkanen AJ, Hakkarainen JJ, Lehtonen M, Venäläinen T, Kääriäinen TM, Jarho E, Suhonen M, Forsberg MM (2011) Brain Pharmacokinetics of Two Prolyl Oligopeptidase Inhibitors, JTP-4819 and KYP-2047, in the Rat. Basic Clinical Pharmacol Toxicol 109:443-451

31. Jalkanen AJ, Leikas JV, Forsberg MM (2014) KYP-2047 Penetrates Mouse Brain and Effectively Inhibits Mouse Prolyl Oligopeptidase. Basic Clinical Pharmacol Toxicol 114:460-3

32. Venäläinen JI, Garcia-Horsman JA, Forsberg MM, Jalkanen A, Wallén EAA, Jarho EM, Christiaans JAM, Gynther J, Männistö PT (2006) Binding kinetics and duration of in vivo action of novel prolyl oligopeptidase inhibitors. Biochem Pharmacol 71:683-692

33. Höfling C, Kulesskaya N, Jaako K, Peltonen I, Männistö PT, Nurmi A, Vartiainen N, Morawski M, Zharkovsky A, Võikar V, Roßner S, García-Horsman JA (2016) Deficiency of prolyl oligopeptidase in mice disturbs synaptic plasticity and reduces anxiety-like behaviour, body weight, and brain volume. Eur Neuropsychopharmacol 6:1048-1061

34. Di Daniel E, Glover CP, Grot E, Chan MK, Sanderson TH, White JH, Ellis CL, Gallagher KT, Uney J, Thomas J, Maycox PR, Mudge AW (2009) Prolyl oligopeptidase binds to GAP-43 and functions without its peptidase activity. Mol Cell Neurosci 41:373-382

35. Paxinos G FK (1997) The Mouse Brain in Stereotaxic Coordinates. Elsevier Academic Press., San Diego

36. Käenmäki M, Tammimäki A, Myöhänen T, Pakarinen K, Amberg C, Karayiorgou M, Gogos JA, Männistö PT (2010) Quantitative role of COMT in dopamine clearance in the prefrontal cortex of freely moving mice.J Neurochem 114:1745-1755

37. Vihavainen T, Relander TRA, Leiviskä R, Airavaara M, Tuominen RK, Ahtee L, Piepponen TP (2008) Chronic nicotine modifies the effects of morphine on extracellular striatal dopamine and ventral tegmental GABA. J Neurochem 107:844-854

38. Parsons LH, Justice JB (1992) Extracellular concentration and in vivo recovery of dopamine in the nucleus accumbens using microdialysis. J Neurochem 58:212218

39. Chefer VI, Thompson AC, Zapata A, Shippenberg TS (2009) Overview of brain microdialysis. Curr Protoc Neurosci:7.1.:1-28

40. Chefer VI, Zapata A, Shippenberg TS, Bungay PM (2006) Quantitative no-netflux microdialysis permits detection of increases and decreases in dopamine uptake in mouse nucleus accumbens. J Neurosci Methods 155:187-193.

41. Smith A, Justice J (1994) The effect of inhibition of synthesis, release, metabolism and uptake on the microdialysis extraction fraction of dopamine. J Neurosci Methods 54:75-82 
42. Justice J (1993) Quantitative microdialysis of neurotransmitters. J Neurosci Methods 48:263-276

43. Airavaara M, Mijatovic J, Vihavainen T, Piepponen TP, Saarma M, Ahtee L (2006) In heterozygous GDNF knockout mice the response of striatal dopaminergic system to acute morphine is altered. Synapse 59:321-329

44. Kumar A, Kopra J, Varendi K, Porokuokka LL, Panhelainen A, Kuure S, Marshall P, Karalija N, Härma M-A, Vilenius C (2015) GDNF Overexpression from the Native Locus Reveals its Role in the Nigrostriatal Dopaminergic System Function. PLoS Genet 11:e1005710

45. Fleming SM, Ekhator OR, Ghisays V (2013) Assessment of sensorimotor function in mouse models of Parkinson's disease. J Visual Exp: JoVE

46. Brooks SP, Dunnett SB (2009) Tests to assess motor phenotype in mice: a user's guide. Nat Rev Neurosci 10:519-529

47. Yorgason JT, España RA, Jones SR (2011) Demon voltammetry and analysis software: analysis of cocaine-induced alterations in dopamine signaling using multiple kinetic measures.J Neurosci Methods 202:158-164

48. Robertson S, Matthies H, Galli A (2009) A closer look at amphetamine-induced reverse transport and trafficking of the dopamine and norepinephrine transporters. Mol Neurobiol 39:73-80

49. Levitt M, Spector S, Sjoerdsma A, Udenfriend S (1965) Elucidation of the ratelimiting step in norepinephrine biosynthesis in the perfused guinea-pig heart. J Pharmacol Exp Therap 148:1-8

50. Peltonen I, Jalkanen AJ, Sinervä V, Puttonen KA, Männistö PT (2010) Different Effects of Scopolamine and Inhibition of Prolyl Oligopeptidase on Mnemonic and Motility Functions of Young and 8-to 9-Month-Old Rats in the Radial-Arm Maze. Basic Clin Pharmacol Toxicol 106:280-287

51. Volkow N, Fowler J, Wang G, Logan J, Schlyer D, MacGregor R, Hitzemann R, Wolf A (1994) Decreased dopamine transporters with age in healthy human subjects. Ann Neurol 36:237-239

52. Volkow N, Wang G-J, Fowler J, Ding Y-S, Gur R, Gatley J, Logan J, Moberg P, Hitzemann R, Smith G (1998) Parallel loss of presynaptic and postsynaptic dopamine markers in normal aging. Ann Neurol 44:143-147

53. Ishibashi K, Ishii K, Oda K, Kawasaki K, Mizusawa H, Ishiwata K (2009) Regional analysis of age-related decline in dopamine transporters and dopamine D2-like receptors in human striatum. Synapse 63:282-290 
Fig. 1 The PREP knock-out (KO) mice had higher extracellular concentrations of dopamine (DA) in the striatum compared to the wild-type (Wt) littermates in the no-net-flux microdialysis study (a). Fast-scan cyclic voltammetry recordings revealed a delayed DA reuptake in the $\mathrm{KO}$ mice. The picture is showing the averaged and normalized single pulse stimulation -evoked DA transients for both genotypes, to illustrate the delayed DA reuptake in the KO mice (b). Heights of DA release peaks were slightly higher in $\mathrm{KO}$ mice but the difference was not statistically significant (c). Half-width (d) and tau values (e) of DA transients were longer in the $\mathrm{KO}$ mice and there was a similar trend in the fall time (f). a: $\mathrm{n}=$ 5-6, b-f: $\mathrm{n}=13-14$. Bars represent mean \pm SEM, ${ }^{*} \mathrm{p}<0.05, * * \mathrm{p}<0.01$, Student's t-test.

Fig. 2 Extracellular striatal concentration of dopamine (DA), its main metabolites DOPAC and HVA, 5-HIAA and GABA was measured in the wild-type (Wt) and PREP knock-out (KO) mice by microdialysis 5 weeks after a supranigral injection of AAV-hPREP or AAV-GFP. Overexpression of PREP did not have an effect on DA (a), DOPAC (c) or HVA (d) but the concentration of 5-HIAA (e) and GABA (f) was increased (Student's t-test). Restoring PREP protein to the $\mathrm{KO}$ mice did not have an effect on the neurotransmitters or their metabolites. AAV-hPREP did not have an effect on amphetamine (AMPH)-induced release of DA in either of the mouse strains (b) but DA release was elevated in the $\mathrm{KO}$ mice compared to the $\mathrm{Wt}$ mice with both concentrations of AMP, $10 \mu \mathrm{M}$ 100-120 min and $30 \mu \mathrm{M}$ 180-200 min (repeated measures, 2-way ANOVA). Bars represent mean \pm SEM, *p $<0.05, * * p<0.01$.

Fig. 3 Wild-type (Wt) and PREP knock-out (KO) mice received supranigral injection of AAVeGFP or AAV-hPREP, and tissue concentrations of neurotransmitters and their metabolites were measured 5 weeks post-injection by tissue HPLC analysis. Overexpression of PREP increased DA (h) and 5-HIAA (l) in the SN but did not have an effect on the levels of striatal (Str) DA (a), its metabolites DOPAC (b and i) and HVA (c and j), 5-HT (d and k), striatal 5HIAA (d), GABA (f and m) or glutamate (GLU) (g and n). Restoring the PREP function to the 
KO mice increased the striatal DA (a) but did not have an effect on the levels of other neurotransmitters or their metabolites. Wt-GFP n=18-21, Wt-PREP n=15-19, KO-GFP n=710, KO-PREP $n=3-7$. Bars represent mean \pm SEM, ${ }^{*} \mathrm{p}<0.05,{ }^{* *} \mathrm{p}<0.01$, Student's t-test. Values were normalized to $100 \%$ (levels in the intact side of the brain).

Fig. 4 PREP knock-out (KO) and wild-type (Wt) littermates had the same amount of dopamine transporters (DAT) in the striatal (Str) (a) and the nigral (SN) (b) tissue, but the levels of phosphorylated DAT (pDAT) were enhanced in the Str of KO mice (c) measured by Western blotting. Tyrosine hydroxylase (TH) levels were increased in the SN (e) but not in the Str (f) of $\mathrm{KO}$ mice. Wt $\mathrm{n}=6-8$, and $\mathrm{KO} \mathrm{n}=8$ (except pDAT SN $\mathrm{n}=3-4)$ in each group. Bars represent means \pm SEM $; * p<0.05, * * p<0.01$, Student's t-test.

Fig. 5 The amount of dopamine transporter (DAT), phosphorylated DAT (pDAT) and tyrosine hydroxylase $(\mathrm{TH})$ in the striatal (Str) and the nigral $(\mathrm{SN})$ tissue was measured by Western blotting 5 weeks after a supranigral injection of AAV-hPREP or AAV-eGFP. Overexpression of PREP increased DAT levels in the Str (a) and in the SN (b), and decreased pDAT in the Str (c) but not in the SN (d). Amount of TH was not changed in the Str (e) or in the SN (f). DAT and TH: $n=6-9$ in each group, pDAT: $n=3-4$ in each group. Bars represent mean \pm SEM, $* \mathrm{p}<0.05$, Student's t-test. 
a 25, Point of no-net-flux

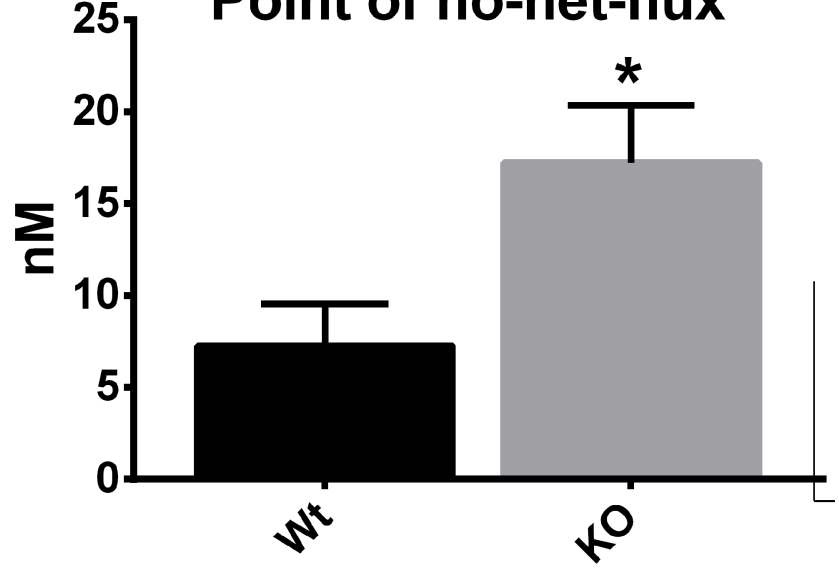

b Single-pulse trace

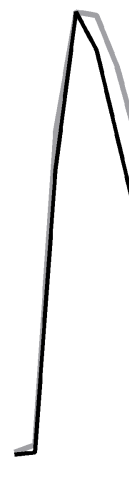

C

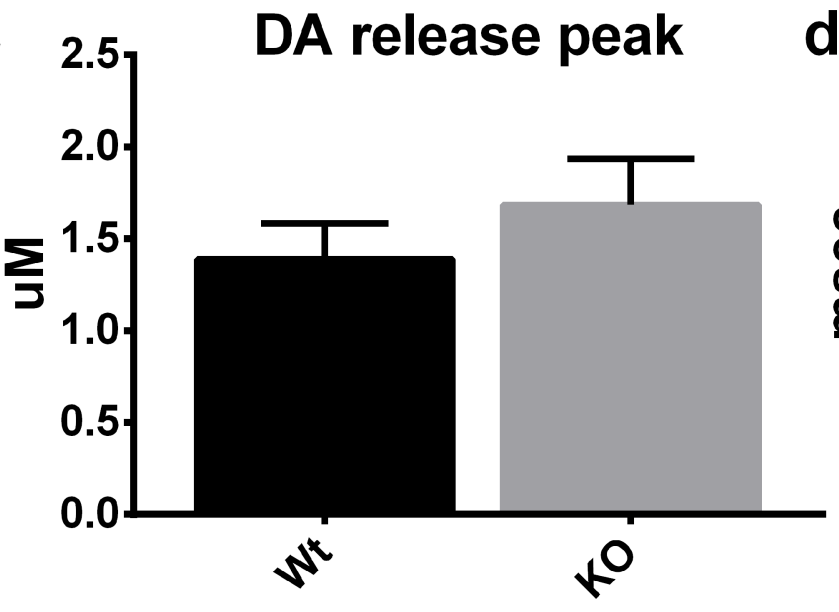

d ${ }_{800} \quad$ Half width

e

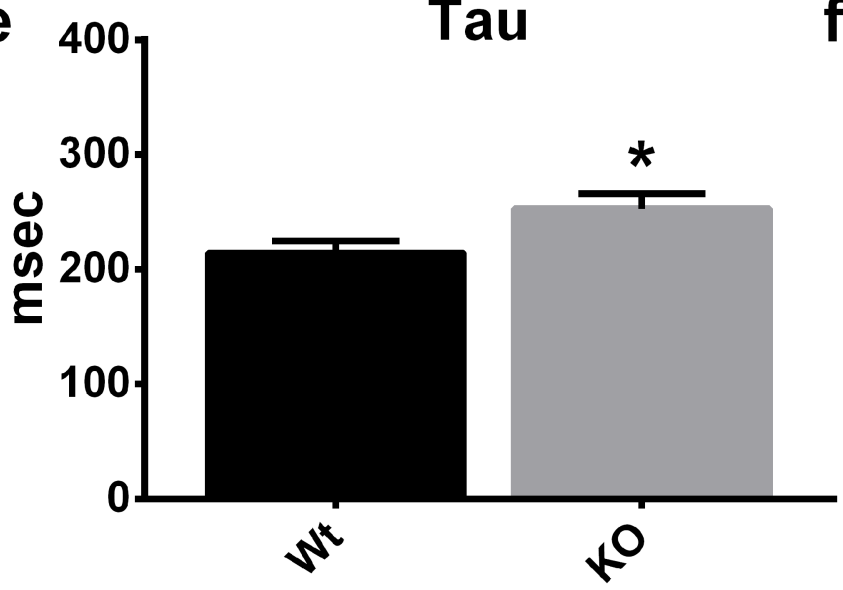

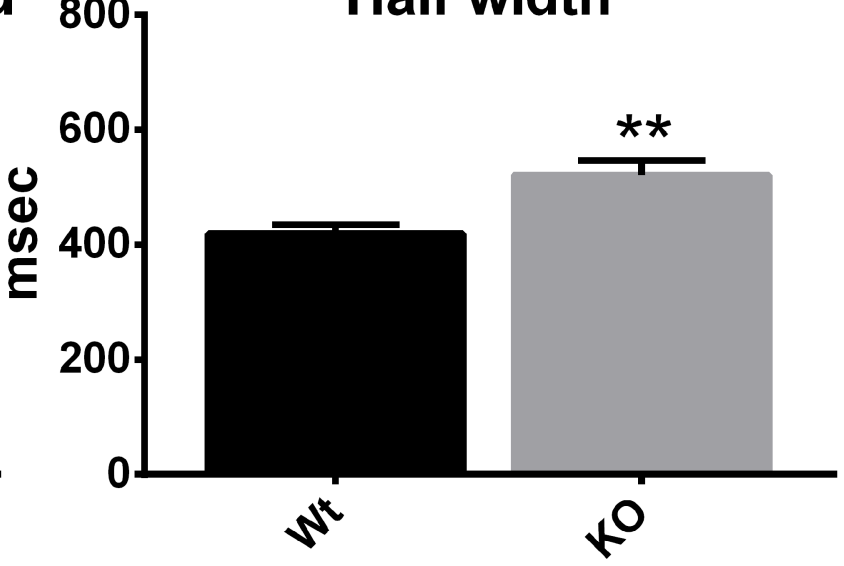

$f$

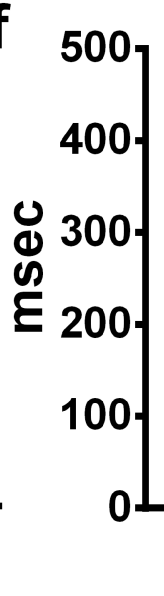

Fall time

$$
p=0.078
$$




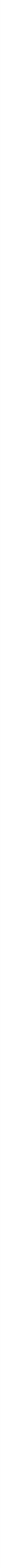


a
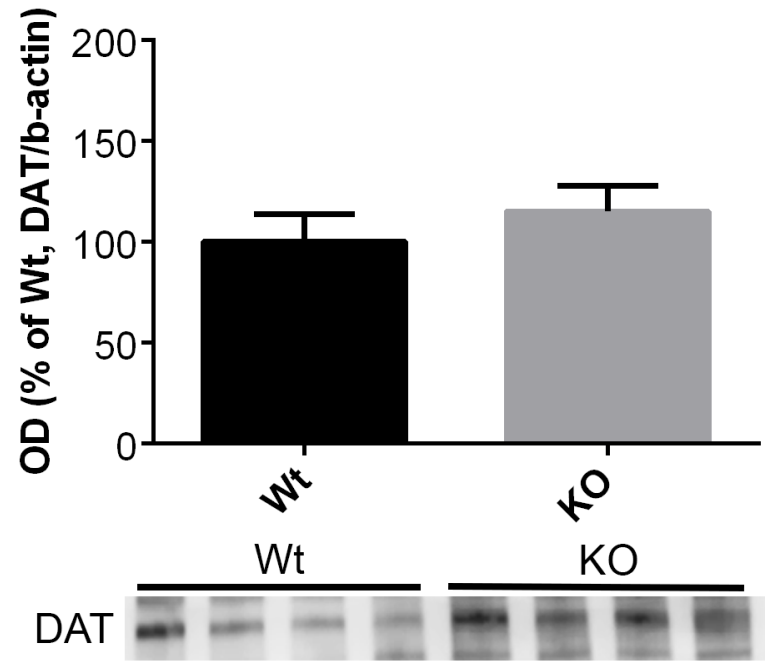
b-actin pDAT Str

C
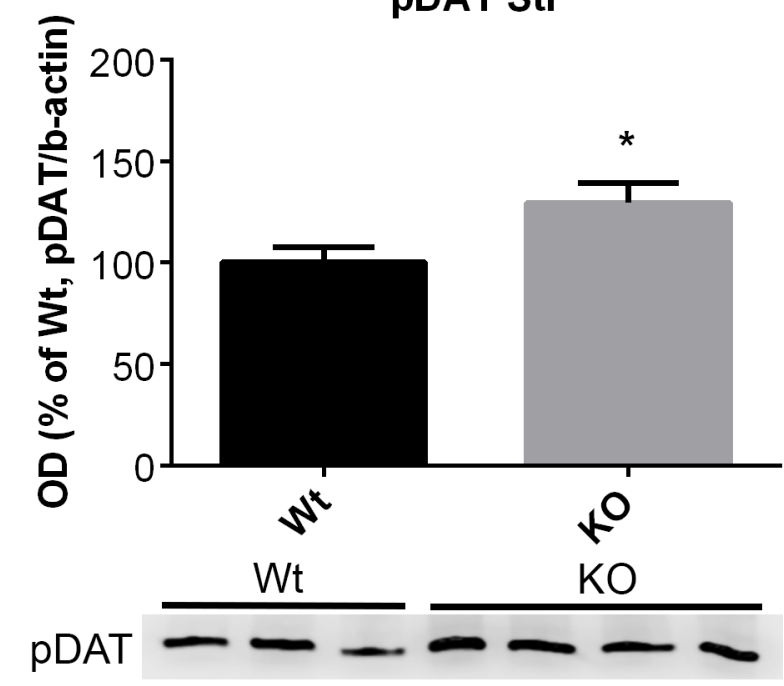

b-actin

TH Str

$\epsilon$

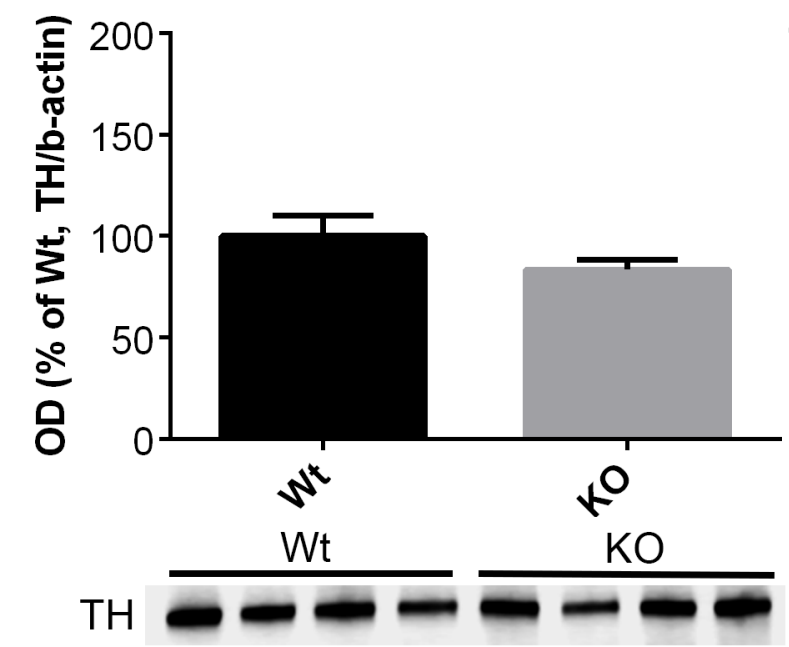

b
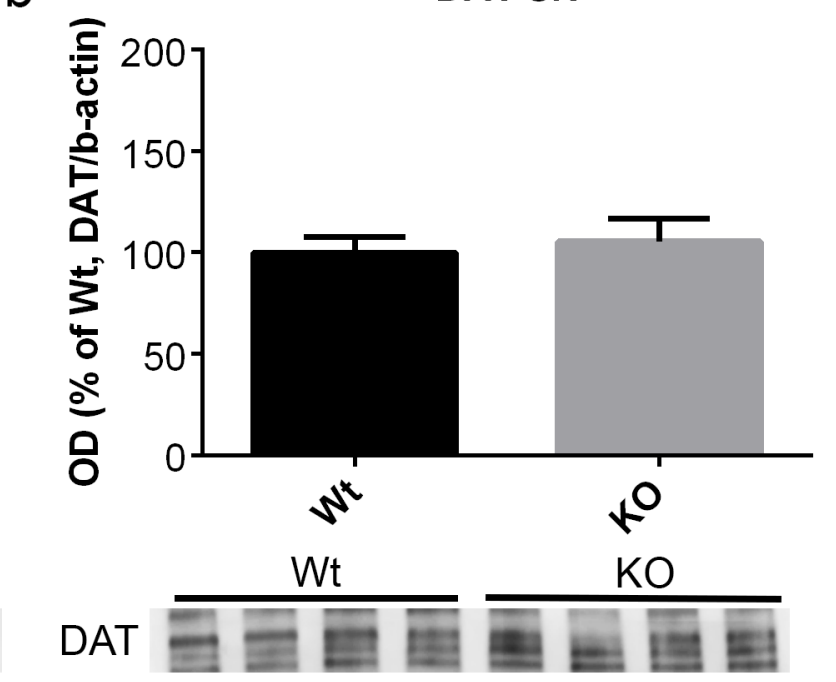
b-actin
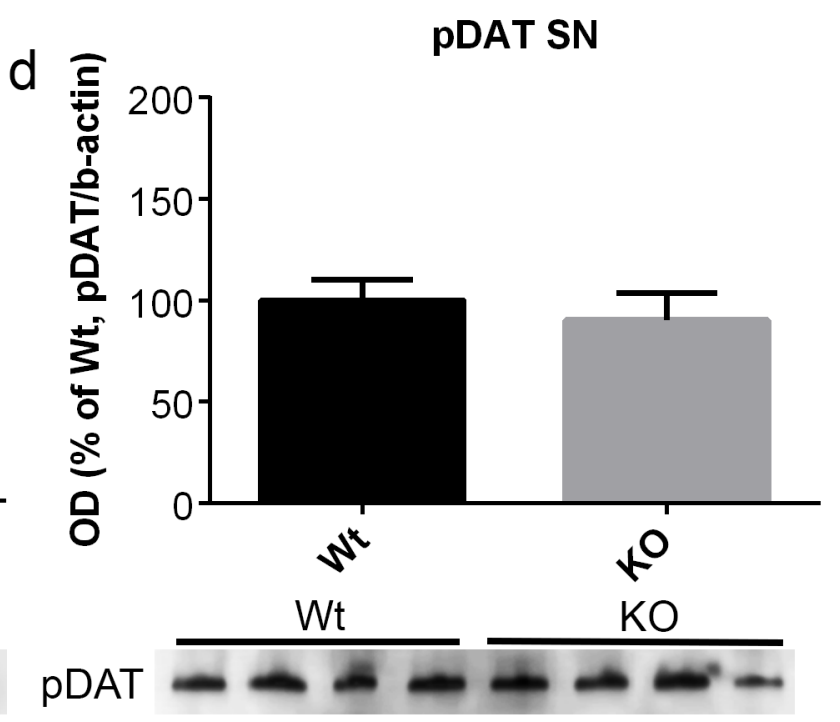
b-actin

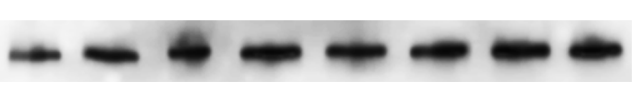

TH SN

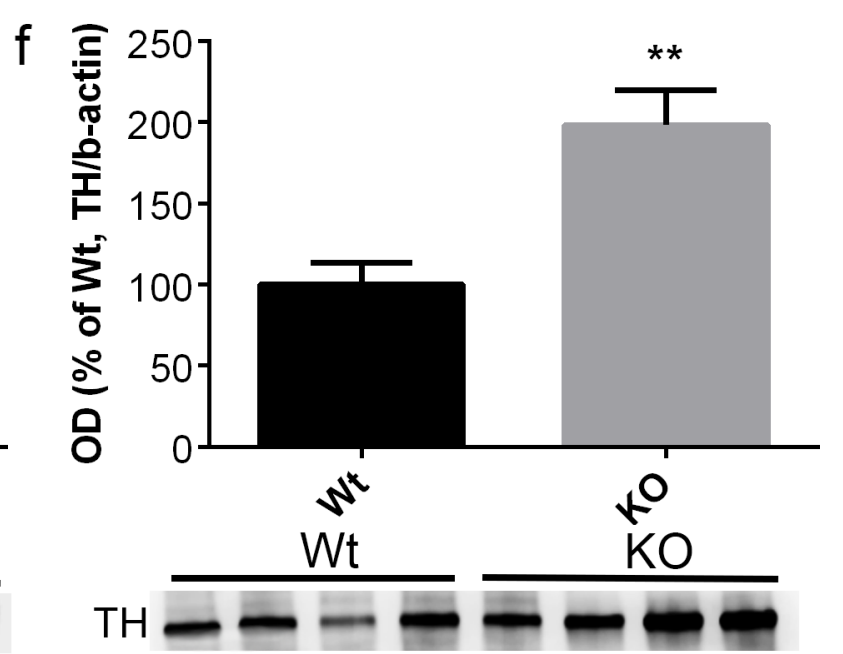




\section{Prolyl oligopeptidase regulates dopamine transporter phosphorylation}

\section{in the nigrostriatal pathway of mouse}

\section{Supplementary material}

Ulrika H Julku${ }^{1}$, Anne E Panhelainen ${ }^{2}$, Saija E Tiilikainen ${ }^{1}$, Reinis Svarcbahs ${ }^{1}$, Anne E Tammimäki $^{1}$, T Petteri Piepponen ${ }^{1}$, Mari H Savolainen ${ }^{1}$, Timo T Myöhänen ${ }^{1}$

${ }^{1}$ University of Helsinki, Division of Pharmacology and Pharmacotherapy, Viikinkaari 5E, P.O. Box 56, 00014 University of Helsinki, Finland

2University of Helsinki, Institute of Biotechnology, Viikinkaari 5D, P.O. Box 56, 00014 University of Helsinki, Finland

Corresponding author: Timo T Myöhänen, timo.myohanen@ helsinki.fi

\section{Characterization of AAV-hPREP}

To target the substantia nigra, AAV1-EF1 $\alpha$-hPREP or AAV1-EF1 $\alpha$-eGFP were given as single injections (volume $1 \mu \mathrm{l}$, rate $0.2 \mu \mathrm{l} / \mathrm{min}$ ) into the left hemisphere, $3.1 \mathrm{~mm}$ anterior and $1.2 \mathrm{~mm}$ lateral to bregma, and $4.2 \mathrm{~mm}$ below the dura (stereotaxic coordinates according to Paxinos and Franklin 1997 [1]).

Tissue processing

At 2 or 4 weeks post-injection mice intended for immunohistochemistry (IHC) analysis were deeply anesthetized with sodium pentobarbital $(150 \mathrm{mg} / \mathrm{kg})$ and transcardially perfused with PBS followed by 4\% paraformaldehyde (PFA) in PBS. Brains were post-fixed for 24-72 hours in $4 \%$ PFA at $4{ }^{\circ} \mathrm{C}$ and transferred to a solution of $10 \%$ sucrose in PBS (pH 7.4; $137 \mathrm{mM} \mathrm{NaCl}$, $2.7 \mathrm{mM} \mathrm{KCl}, 10 \mathrm{mM} \mathrm{Na}_{2} \mathrm{HPO}_{4}, 1.8 \mathrm{mM} \mathrm{KH}_{2} \mathrm{PO}_{4}$ ) and incubated overnight at $4{ }^{\circ} \mathrm{C}$. On the next day, tissues were transferred to $30 \%$ sucrose solution in PBS until brains sank to the 
bottom of vial. Brains were frozen on dry ice and were kept at $-80{ }^{\circ} \mathrm{C}$ until sectioning. Frozen brain sections were sectioned as $30 \mu \mathrm{m}$ free-floating sections on a cryostat (Leica CM3050, Wetzlar, Germany) and kept in a cryoprotectant solution (30\% ethylene glycol and 30\% glycerol in $0.5 \mathrm{M}$ phosphate buffer). Mice intended for PREP enzymatic activity assay were transcardially perfused with ice-cold PBS, and thereafter brains were frozen in isopentane on dry ice and kept at $-80{ }^{\circ} \mathrm{C}$ until further analyses.

\section{PREP immunohistochemistry}

PREP IHC was modified from Myöhänen et al [2]. In brief, the endogenous peroxidase activity was inactivated with $10 \%$ methanol and $3 \%$ hydrogen peroxide $\left(\mathrm{H}_{2} \mathrm{O}_{2}\right)$ solution in PBS $(\mathrm{pH}$ 7.4) for $10 \mathrm{~min}$, and non-specific binding was blocked for $30 \mathrm{~min}$ with $10 \%$ normal goat serum (S-1000, Vector laboratories, Peterborough, UK), after which the sections were incubated overnight in rabbit anti-PREP primary antibody (dilution 1:500 in 1\% normal serum in PBS containing $0.5 \%$ Triton-X-100; custom made polyclonal ab, raised against PREP specific peptide DPDSEQTKAFVEAQNK (PREP-33:48); Thermo Fisher Scientific, MA, USA). The specificity of PREP antibody was verified by using purified porcine PREP protein and Wt/PREP-KO mice tissue homogenates a (as described in methods, PREP antibody dilution 1:500). Subsequently, the sections were placed in goat anti-rabbit secondary antibodies for $2 \mathrm{~h}$ (dilution 1:500 in 1\% normal serum in PBS containing 0.5\% Triton-X-100; \#31460, Thermo Fisher Scientific). The antigen-antibody complexes were identified following incubation with $0.05 \%$ 3,3'-diaminobenzidine (DAB) and $0.03 \% \mathrm{H}_{2} \mathrm{O}_{2}$ solution. Finally, the sections were transferred to glass slides, dehydrated in alcohol series and mounted with Depex (BDH, UK).

\section{Brain homogenization and PREP activity assay}

For PREP activity assay, brains were stored at $-80{ }^{\circ} \mathrm{C}$ until dissection. Cortex samples were homogenized in 10 vol. of assay buffer (0.1 M Na-K-phosphate buffer, $\mathrm{pH} 7.0)$ and centrifuged at $14,000 \mathrm{~g}$ at $4{ }^{\circ} \mathrm{C}$ for $20 \mathrm{~min}$. The supernatants were collected and used for the activity assay as previously described [3]. Briefly, the brain homogenate was pre-incubated with assay buffer for $30 \mathrm{~min}$ at $37^{\circ} \mathrm{C}$. Substrate (4 mM Suc-Gly-Pro-AMC; Bachem, Switzerland) was added to initiate the reaction with $1 \mathrm{mM}$ final concentration in the plate, and the incubation continued for $60 \mathrm{~min}$ at $37^{\circ} \mathrm{C}$. The reaction was stopped with $1 \mathrm{M}$ sodium acetate buffer ( $\mathrm{pH}$ 4.2). The formation of 7-amino-4-methylcoumarin (AMC; Bachem, Switzerland) was measured using The Wallac 1420 Victor fluorescence plate reader (PerkinElmer, Waltham, MA, USA). The excitation and emission wavelengths were 360 and $460 \mathrm{~nm}$, respectively. The protein 
concentration of brain homogenate was determined using a BCA protein assay kit (Thermo Scientific, USA).

Fast-scan cyclic voltammetry

Male mice (5-6 months of age) were decapitated and $300 \mu \mathrm{m}$ thick coronal brain slices that contained the cortex and the striatum were cut on a vibratome (7000 smz-2, Campden Instruments, England) in ice-cold cutting saline containing $125 \mathrm{mM} \mathrm{NaCl}, 2.5 \mathrm{mM} \mathrm{KCl}, 26$ $\mathrm{mM} \mathrm{NaHCO} 3,0.3 \mathrm{mM} \mathrm{KH} \mathrm{PO}_{4}, 3.3 \mathrm{mM} \mathrm{MgSO}_{4}, 0.8 \mathrm{mM} \mathrm{NaH}_{2} \mathrm{PO}_{4}$, and $10 \mathrm{mM}$ glucose. Slices were allowed to recover for $1-2$ hours at $32{ }^{\circ} \mathrm{C}$ in a holding chamber with oxygenbubbled $\left(95 \% \mathrm{O}_{2}, 5 \% \mathrm{CO}_{2}\right)$ recording saline containing $125 \mathrm{mM} \mathrm{NaCl}, 2.5 \mathrm{mM} \mathrm{KCl}, 26 \mathrm{mM}$ $\mathrm{NaHCO}_{3}, 0.3 \mathrm{mM} \mathrm{KH}_{2} \mathrm{PO}_{4}, 2.4 \mathrm{mM} \mathrm{CaCl}_{2}, 1.3 \mathrm{mM} \mathrm{MgSO}_{4}, 0.8 \mathrm{mM} \mathrm{NaH}_{2} \mathrm{PO}_{4}$, and $10 \mathrm{mM}$ glucose. In the recording chamber the slices were continuously perfused with $35^{\circ} \mathrm{C}$ oxygenbubbled recording saline. In amphetamine (d-amphetamine hemi-sulfate, Sigma-Aldrich) experiments the drug was added to the perfusate $(5 \mathrm{uM})$ after a stable baseline of stimulated transient peaks was reached. Fast-scan cyclic voltammetry recordings were performed with cylindrical $5 \mu \mathrm{m}$ carbon fiber electrodes positioned at the dorsal striatum $\sim 50 \mu \mathrm{m}$ below the slice surface. Striatal slices were electrically stimulated using a bipolar stainless steel electrode placed at a distance of $\sim 100 \mu \mathrm{m}$ from the recording electrode. Square pulses of $0.2 \mathrm{sec}$ duration were produced by DS3 stimulator (Digitimer Ltd, UK) that was triggered by a Master-8 pulse generator (A.M.P.I., Israel). Stimulus magnitude was selected by plotting a current-response curve to single pulse stimulations and selecting the minimum value that reliably produced the maximal response. Triangular voltage ramps from $-450 \mathrm{mV}$ holding potential to $+900 \mathrm{mV}$ over $9 \mathrm{~ms}$ (scan rate of $300 \mathrm{mV} / \mathrm{ms}$ ) were applied to the carbon fiber electrode at $100 \mathrm{~ms}$ intervals. Current was recorded with an Axopatch 200B amplifier (Molecular Devices LLC, CA, USA) filtered with $5 \mathrm{kHz}$ low-pass Bessel filter and digitized at $40 \mathrm{kHz}$ (ITC-18 board, InstruTech, NY, USA). Triangular wave generation and data acquisition were controlled and the recorded transients were characterized by a computer routine in IGOR Pro (WaveMetrics Inc,OR, USA) [4,5]. Background-subtracted cyclic voltammograms, obtained with 1 uM DA solution (DA$\mathrm{HCl}$ ), were used to calibrate the electrodes. The DA terminals were stimulated either with single electrical pulses at 2 min intervals; paired stimulations at fixed intervals of $60,30,10$ and $5 \mathrm{sec}$ to study paired stimulation depression or by a burst stimulation of 5 pulses at $20 \mathrm{~Hz}$, to study the release probability of the terminals. 
HPLC

Concentration of DA, its metabolites and 5-HIAA in dialysate was measured by HPLC with electrochemical detection as earlier described [6] with slight modifications and the concentration of gamma-aminobutyric acid (GABA) was measured by HPLC with fluorescence detection as earlier described [7] with slight modifications. Tissue concentration of DA, 5-HT and their metabolites were measured as earlier described [8] with slight modifications.

HPLC system for determination of extracellular concentration of DA, its metabolites and 5HIAA consisted of a solvent delivery pump (Jasco model PU-2080 Plus, Jasco International Co, Japan), pulse damper (SSI LP-21, Scientific Systems, State College, PA, USA), a refrigerated autosampler (Shimadzu SIL-20AC Autosampler, Shimadzu Co, Japan), an analytical column (Kinetex C-18 $5 \mu \mathrm{m}, 4.60$ x $50 \mathrm{~mm}$, Phemomenex Inc, USA) thermostated by a column heater (CROCO CIL, Cluzeau Info-Labo, France and LaChrom L-7350, Merck, Germany), an electrochemical detector (ESA Coulochem II detector, ESA Biosciences, MA, USA) and a model 5014B microdialysis cell (ESA Biosciences, MA, USA). The mobile phase consisted of $0.1 \mathrm{M} \mathrm{NaH}_{2} \mathrm{PO}_{4}$ buffer (Merck, Germany), $8 \%$ (v/v) methanol (Merck), $0.2 \mathrm{M}$ ethylenediaminetetraacetic acid, $100 \mathrm{mg} / \mathrm{L}$ octanesulphonic acid, $\mathrm{pH} 4.0$ and the flow rate was $1.0 \mathrm{~mL} / \mathrm{min}$. detector and a model 5014B microdialysis cell (ESA). DA was reduced with an amperometric detector (potential $-120 \mathrm{mV}$ against an $\mathrm{Ag} / \mathrm{AgCl}$ reference electrode) after being oxidized with a coulometric detector $(+300 \mathrm{mV})$; DOPAC and HVA were oxidized with the coulometric detector. Injection volume was $20 \mu \mathrm{L}$ for conventional microdialysis samples and $15 \mu \mathrm{L}$ for no-net-flux microdialysis samples. The column temperature was kept at $45^{\circ} \mathrm{C}$. The chromatograms were processed by AZUR chromatography data system software (Cromatek, Essex, UK).

The HPLC system for determination of the tissue concentration of DA, 5-HT and their metabolites consisted of a solvent delivery pump (ESA Model 582, ESA Biosciences), a refrigerated autosampler (Shimadzu SIL-20AC, Shimadzu Corp, Japan), a microdialysis cell (ESA Model 5014B, ESA Biosciences), an analytical column (Kinetex C-18 2.6 $\mu \mathrm{m}, 4.6$ x 50 $\mathrm{mm}$, Phenomenix Inc, USA) thermostated by a column heater (CROCO-CIL, Cluzeau Info Lab), a pulse damper (SSI LP-21, Scientific Systems, State College, PA, USA) and an electrochemical detector (ESA CoulArray 5600A, ESA Biosciences). The mobile phase consisted of $0.1 \mathrm{M} \mathrm{NaH}_{2} \mathrm{PO}_{4}$ buffer, $200 \mathrm{mg} / \mathrm{l}$ of octane sulfonic acid, methanol (10\%), and 
$0.2 \mathrm{M}$ EDTA, and the flow-rate was $1.0 \mu \mathrm{L} / \mathrm{min}$ Injection volume was $100 \mu \mathrm{L}$. The column temperature was kept at $45{ }^{\circ} \mathrm{C}$. Chromatograms were processed and concentrations of monoamines calculated using CoulArray for Windows software (ESA Biosciences).

The HPLC system for determination of the extracellular concentration of GABA consisted of a solvent delivery pump (Jasco model PU-1580 HPLC Pump, Jasco International Co, Japan) connected to an online degasser (Jasco 3-Line Degasser, DG-980-50) and a ternary gradient unit (Jasco LG-1580-02), a refrigerated autosampler (Shimadzu NexeraX2 SIL-30AC Autosampler, Shimadzu Corp), an analytical column (Kinetex C-18 $5 \mu \mathrm{m}, 4.60$ x 50 mm, Phemomenex Inc) protected by a $0.5-\mathrm{mm}$ inlet filter and thermostated by a column heater (CROCO-CIL, Cluzeau Info-Labo, France), and a fluorescence detector (Jasco Intelligent Fluorescence Detector model FP-1520). The wavelengths of the fluorescence detector were set to 330 (excitation) and 450 (emission). The mobile phase consisted of $0.1 \mathrm{M} \mathrm{NaH}_{2} \mathrm{PO}_{4}$ buffer (Merck), pH 4.9 (adjusted with $\mathrm{Na}_{2} \mathrm{HPO}_{4}$ ), $20 \%$ (v/v) acetonitrile (Merck), and the flow-rate was $1.2 \mathrm{~mL} / \mathrm{min}$. Automated sample derivatization was carried out using the autosampler at 8 ${ }^{\circ} \mathrm{C}$. The autosampler was programmed to add $6 \mu \mathrm{L}$ of the derivatizing reagent $(3 \mu \mathrm{L}$ of mercaptoethanol ad $1 \mathrm{~mL}$ of o-phtaldialdehyde) to $15 \mu \mathrm{L}$ of a microdialysis sample, to mix two times, and to inject $20 \mu \mathrm{L}$ onto the column after a reaction time of $1 \mathrm{~min}$. The chromatograms were processed by AZUR chromatography data system software (Cromatek, Essex, UK).

The tissue concentrations of GABA and glutamate were analyzed with HPLC equipped with a fluorescence detector. Injection volume was $10 \mu \mathrm{L}$ and mobile phase consisted $15 \%(\mathrm{v} / \mathrm{v})$ acetonitrile in glutamate measurement, otherwise the method was similar than GABA analysis of microdialysis samples as described above.

\section{Nigral microinjection of AAV-hPREP increases PREP activity in nigrostriatal tract}

To characterize the distribution and function of viral vectors, we injected unilaterally AAV1EF1 $\alpha$-eGFP or AAV1-EF1 $\alpha$-hPREP above SN to Wt mice and examined the PREP enzyme activity in striatal tissue 4 weeks post-injection (Fig. S1) and PREP expression in 2 and 4 weeks post-injection by immunohistochemistry (Fig. S2). AAV-PREP increased PREP activity unilaterally approximately 2 -fold in striatal tissue (AAV-PREP injected vs. intact striatum $\mathrm{F}_{3,15}$ $=15.536, \mathrm{p}=0.00070,1$-way ANOVA, Bonferroni post-test) but AAF-GFP did not have effect on PREP activity (Fig. S1; AAV-GFP vs. AAV-PREP F $3,15=15.536, p=0.00041$, 1-way ANOVA, Bonferroni post-test). PREP overexpression was observed unilaterally in SN 2 weeks post-injection, and in both SN and striatum 4 weeks post-injection (Fig. S2). 


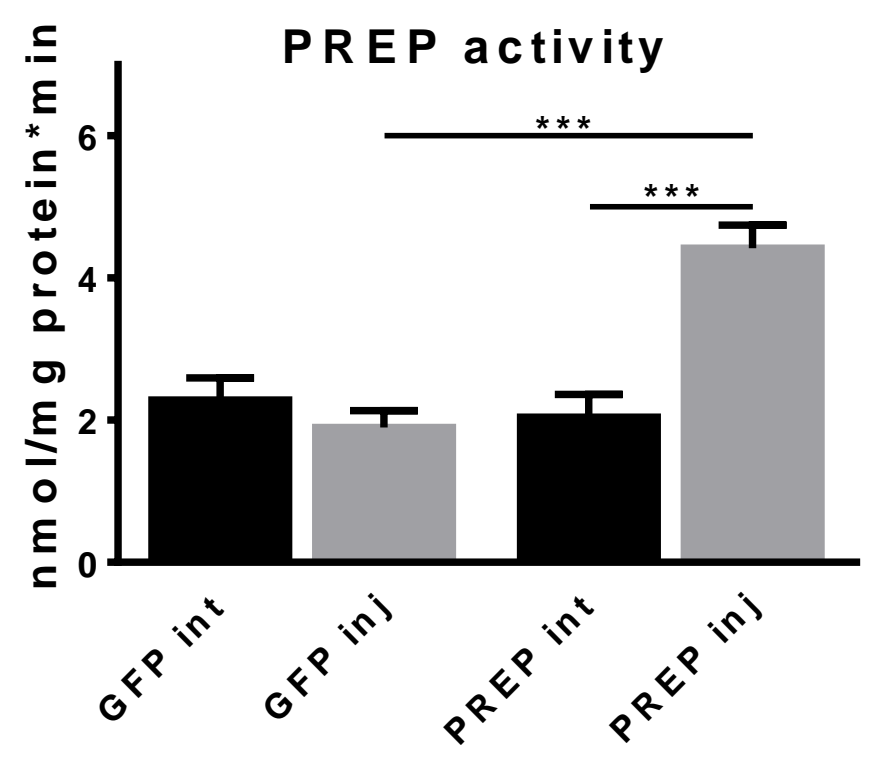

Fig. S1 PREP activity in the striatal tissue was measured 4 weeks after a nigral injection of AAV-PREP. AAV-PREP increased PREP activity unilaterally (intact vs. injected striatum) and AAV-GFP did not have an effect on PREP activity. $n=4$ in each group. Bars represent mean \pm SEM, $* * * p<0.001,1$-way ANOVA, Bonferroni post-test. 


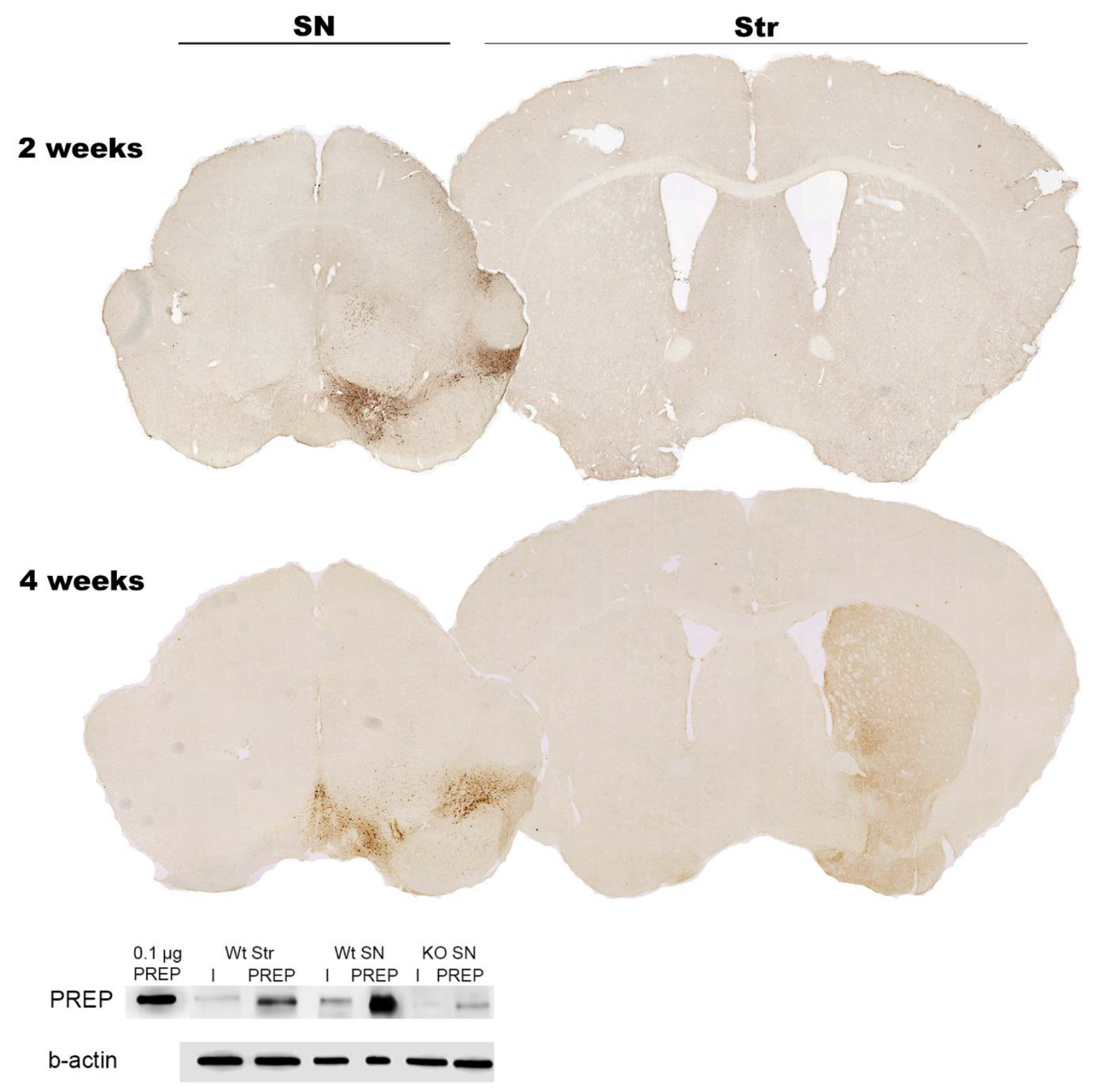

Fig. S2 PREP expression after a unilateral nigral injection of AAV-PREP. AAV-PREP was injected to the point above substantia nigra (SN) and PREP was stained in the striatum (Str) and in the SN by immunohistochemistry 2 and 4 weeks post-injection. Unilateral PREP staining can be detected in the SN 2 weeks post-injection and in both SN and Str 4 weeks postinjection. The specificity of PREP antibody was verified by using $0.1 \mu \mathrm{g}$ of purified porcine PREP protein and intact (I) or AAV-PREP (PREP) injected striatal (Str) and nigral (SN) tissue homogenates of wild-type (Wt) or PREP-KO mice (KO). 

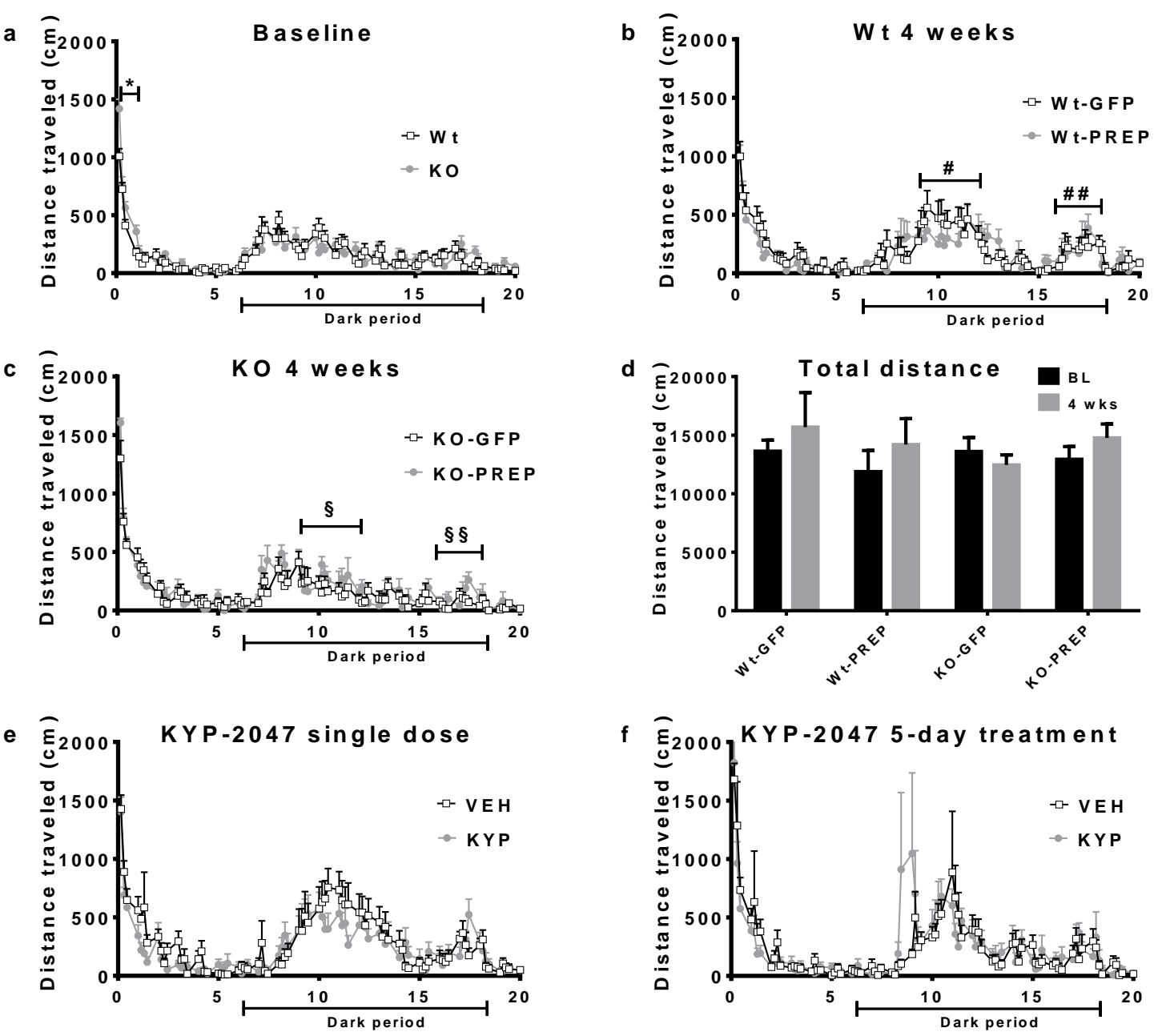

Fig. S3 Wild-type (Wt) and PREP knock-out (KO) mice received a nigral injection of AAVGFP or AAV-PREP unilaterally and a 20-hour spontaneous locomotor activity test was performed before the injections and 4 weeks after the injections. The $\mathrm{KO}$ mice showed enhanced explorative behavior (a)(0-1 h: $\mathrm{F}_{1,22}=7.567$, ${ }^{*} \mathrm{p}=0.012$, repeated measures 2-way ANOVA) but they were less active than the Wt mice during the dark period in the $2^{\text {nd }}$ test (bc) (genotype effect 9-12 h, \# vs. $\$: F_{1,18}=3.637, p=0.073,16-18$ h, \#\# vs. $\$$ : $F_{1,18}=5.626$, $* p=0.029$, repeated measures 2-way ANOVA). Nigrostriatal PREP overexpression (b) or restoring PREP function (c) did not have an effect on the locomotor activity. There were no differences in the total distance (d). Single dose (e) or 5-day treatment (f) with PREP inhibitor (KYP-2047) did not have an effect on locomotor activity in the Wt mice. a: $n=12$ in each group, b-d: $\mathrm{n}=5-6$ in each group, e-f: $\mathrm{n}=10-11$ in each group. Bars represent mean \pm SEM. 

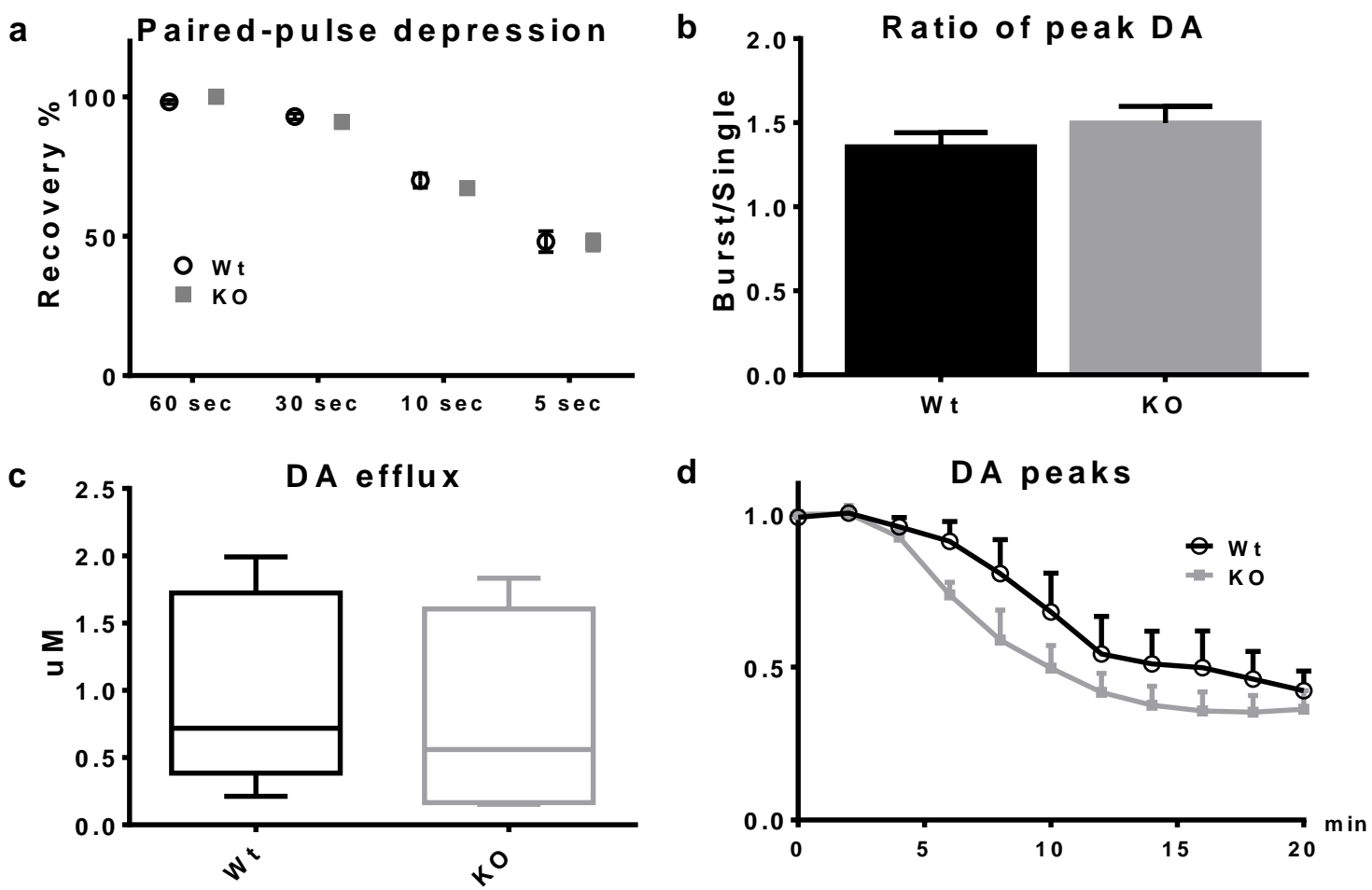

Fig. S4 Paired-pulse and amphetamine-induced DA release in acute striatal slices in the wildtype (Wt) and PREP knock-out (KO) mice measured by fast-scan cyclic voltammetry. Paired pulse depression recovery (a), ratio of peak DA (b), amphetamine-induced DA efflux (c) and DA peaks (d) were similar in the $\mathrm{Wt}$ and $\mathrm{KO}$ mice. $\mathrm{n}=4-6$ Bars represent mean \pm SEM.

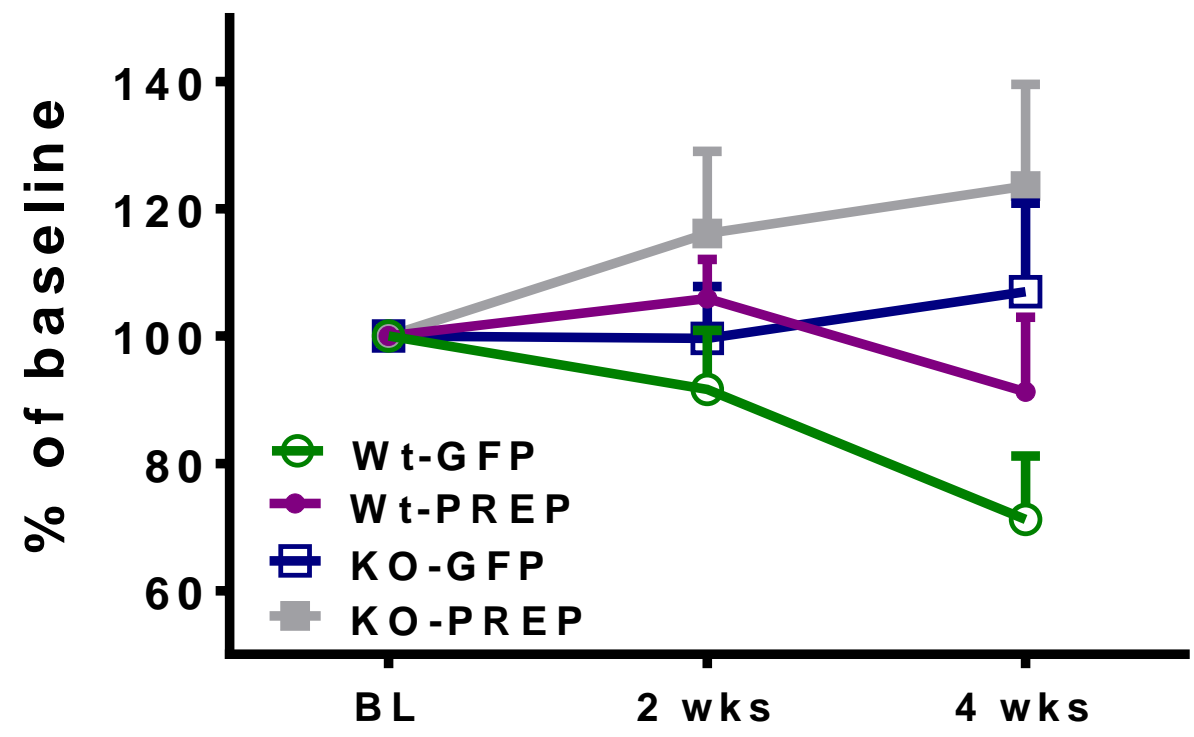


Fig. S5 Paw preference was measured before and after a unilateral nigral injection of AAVGFP or AAV-PREP by cylinder test. GFP decreased the use of contralateral paw in the wildtype (Wt) mice (BL vs. 4 wks *p<0.05) but overexpression of PREP did not have effect on paw preference in the Wt mice. Restoring PREP function to the PREP knock-out (KO) mice increased the use of contralateral paw (BL vs. 4 wks, ${ }^{*}$ p $<0.05$ ) but GFP did not have an effect on the paw preference in KO mice. $\mathrm{n}=6-11$ in each group. Bars represent mean \pm SEM. Use of contralateral paw was calculated as per cent of baseline level that was set as $100 \%$.
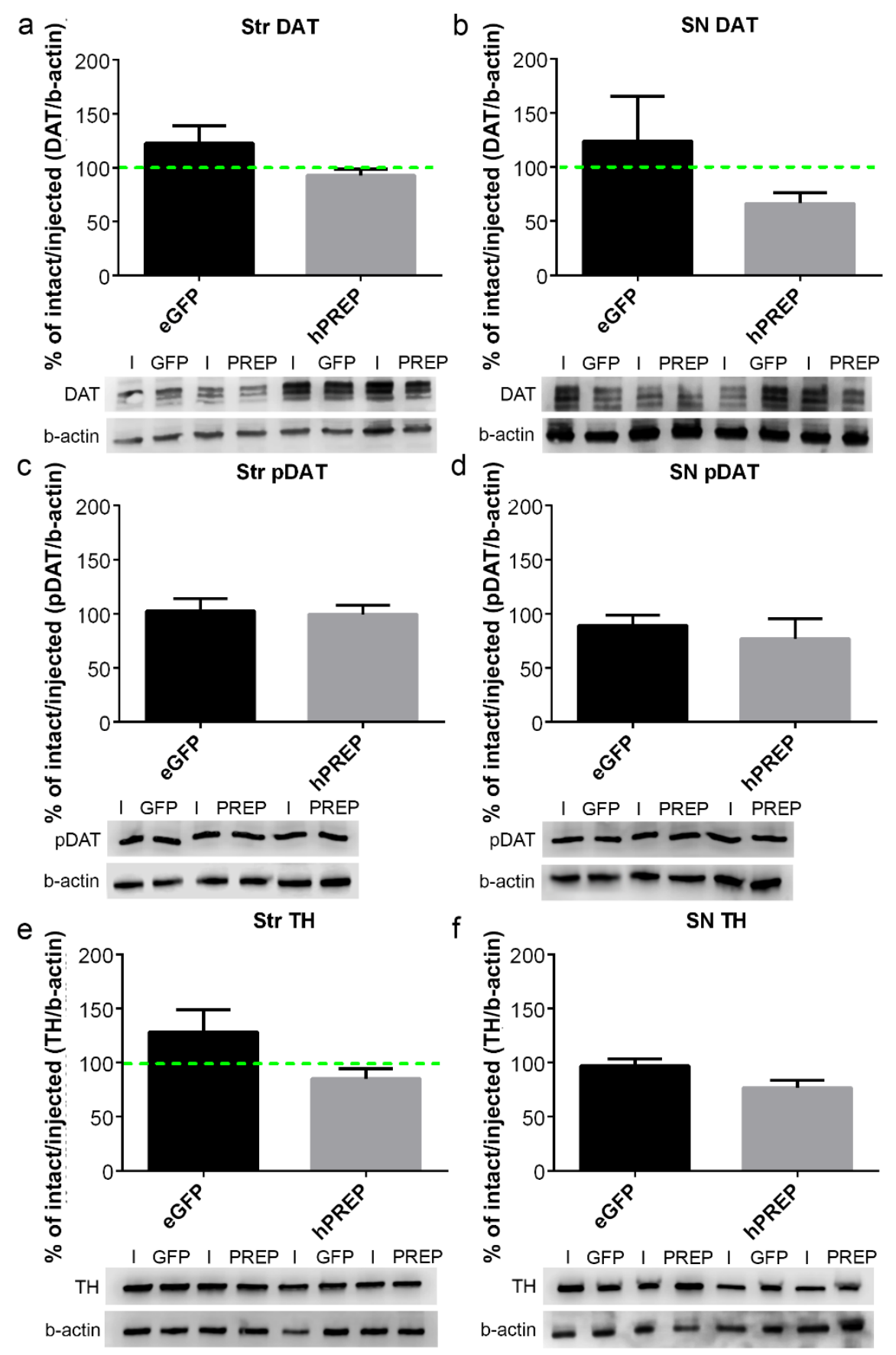
Fig. S6 Restoring PREP function to the PREP knock-out (KO) mice did not have an effect on dopamine transporter (DAT) (a-d) or tyrosine hydroxylase (TH) (e-f). PREP function was restored to the KO mice by a nigral injection of AAV-hPREP. Level of DAT, phosphorylated DAT (pDAT) and TH was measured by Western blotting 5 weeks post-injection in the striatal and nigral tissue. $\mathrm{n}=4$ in each group. Bars represent mean \pm SEM. 

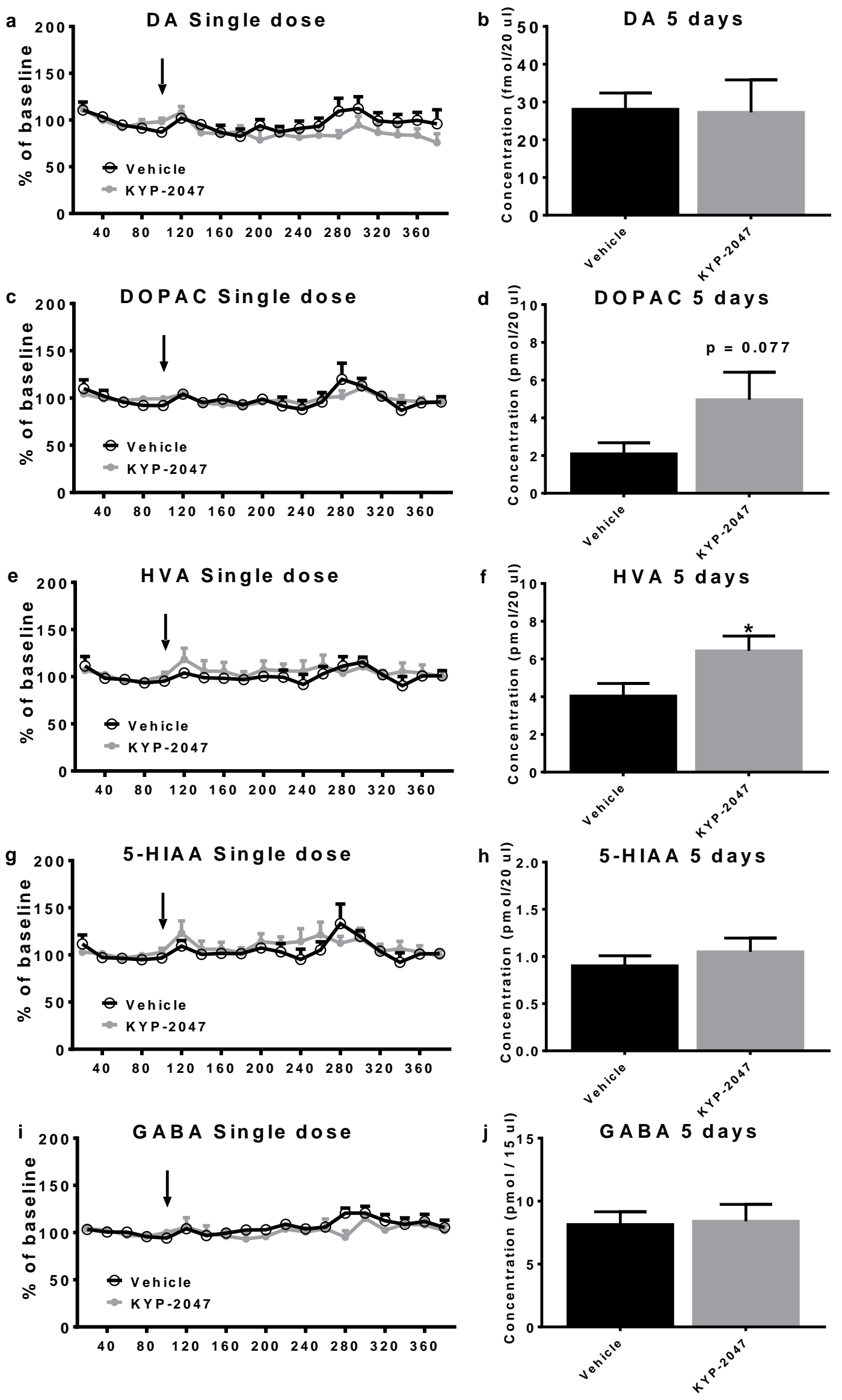
Fig. S7 The effect of a single dose or 5-day treatment with PREP inhibitor (KYP-2047) on striatal neurotransmitters and metabolites was measured by striatal microdialysis. The single dose of KYP-2047 (injection marked with arrow) did not have an effect on the level of dopamine (DA) (a), its metabolites DOPAC (c) and HVA (e), 5-HIAA (g) or GABA (i). The 5-day treatment did not have an effect on the level of DA (b), 5-HIAA (h) or GABA (j) but HVA level (f) was increased and there was a similar trend in DOPAC (d). $n=7-10$ in each group. Bars represent mean $\pm \mathrm{SEM}, * \mathrm{p}<0.05$, Student's t-test.

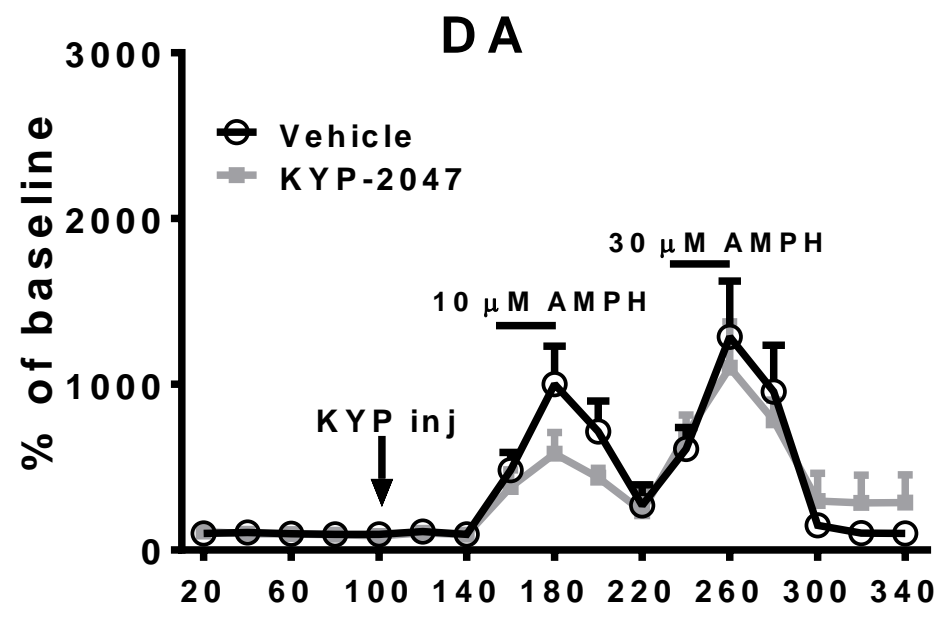

Fig. S8 The effect of PREP inhibition on amphetamine induced dopamine (DA) release. PREP inhibitor (KYP-2047) did not have a statistically significant effect on amphetamine-induced (AMPH) DA release. 

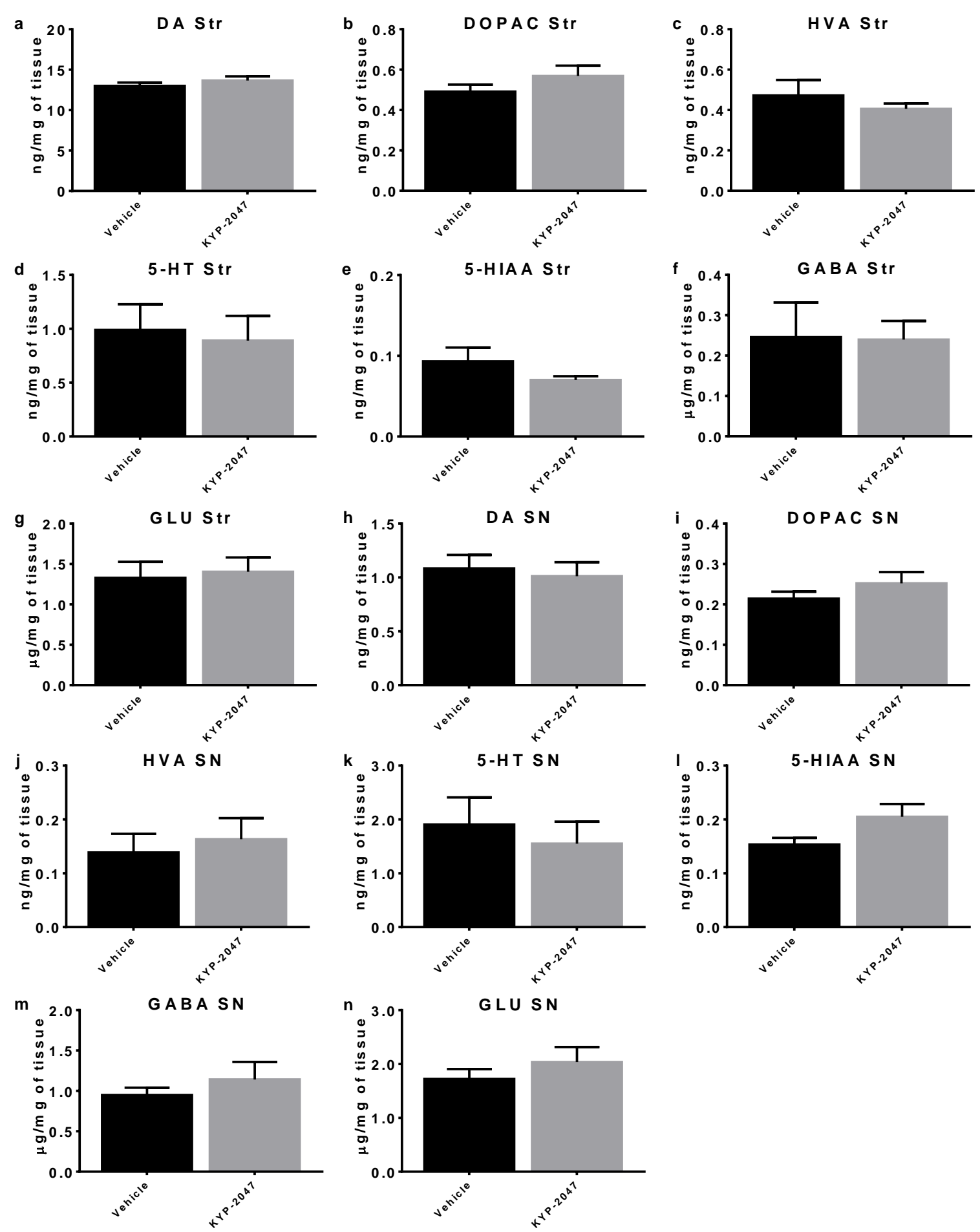

Fig. S9 A 5-day treatment with PREP inhibitor (KYP-2047) did not have an effect on the striatal (Str) or nigral (SN) level of dopamine (DA) (a and h), its metabolites DOPAC (b and i) and HVA (c and j), 5-HT (d and k), its metabolite 5-HIAA (e and l), GABA (f and m) or glutamate (GLU) ( $\mathrm{g}$ and $\mathrm{n}$ ) in tissue HPLC analysis. 


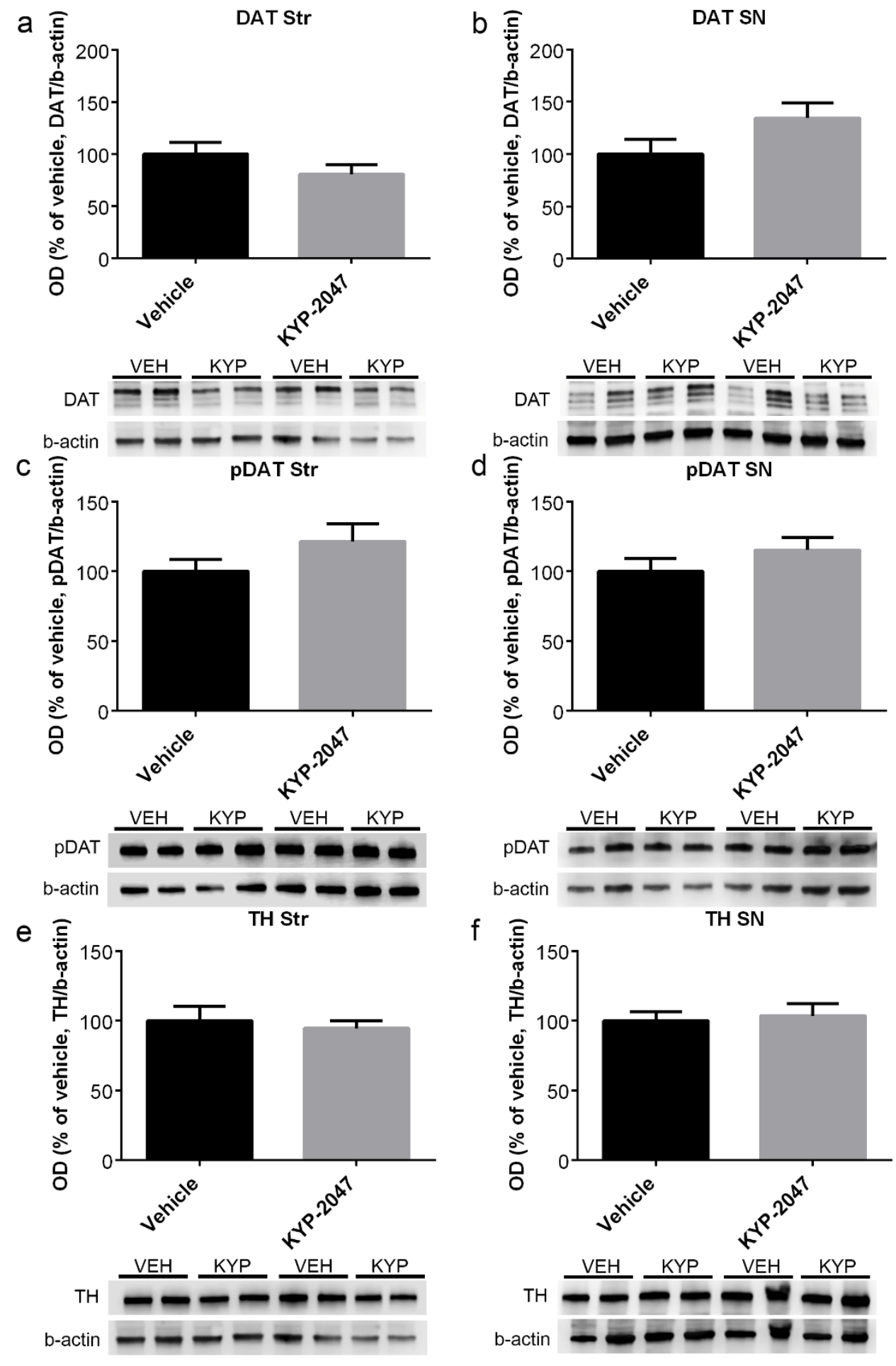

Fig. S10 PREP inhibition did not have an effect on dopamine transporter (DAT) or tyrosine hydroxylase (TH) in the nigrostriatal tract. DAT (a-b), phosphorylated DAT (pDAT) (c-d) and TH (e-f) in the striatal (Str) and nigral (SN) tissue were measured by Western blotting after a 5-day treatment with PREP inhibitor (KYP-2047) or vehicle. $\mathrm{n}=5-8$ in each group. Bars represent mean \pm SEM, Student's t-test. 


\section{References}

1. Paxinos G FK (1997) The Mouse Brain in Stereotaxic Coordinates. Elsevier Academic Press., San Diego

2. Myöhänen TT, Venäläinen JI, Tupala E, Garcia-Horsman JA, Miettinen R, Männistö PT (2007) Distribution of Immunoreactive Prolyl Oligopeptidase in Human and Rat Brain. Neurochem Res 32:1365-1374

3. Myöhänen TT, Venäläinen JI, García-Horsman JA, Piltonen M, Männistö PT (2008) Distribution of prolyl oligopeptidase in the mouse whole-body sections and peripheral tissues. Histochem Cell Biol 130:993-1003

4. Mosharov EV (2008) Analysis of single-vesicle exocytotic events recorded by amperometry. Exocyt Endocyt 440:315-327

5. Mosharov EV, Sulzer D (2005) Analysis of exocytotic events recorded by amperometry. Nature methods 2:651-658

6. Käenmäki M, Tammimäki A, Myöhänen T, Pakarinen K, Amberg C, Karayiorgou M, Gogos JA, Männistö PT (2010) Quantitative role of COMT in dopamine clearance in the prefrontal cortex of freely moving mice. J Neurochem 114:1745-1755

7. Vihavainen T, Relander TRA, Leiviskä R, Airavaara M, Tuominen RK, Ahtee L, Piepponen TP (2008) Chronic nicotine modifies the effects of morphine on extracellular striatal dopamine and ventral tegmental GABA. J Neurochem 107:844-854

8. Airavaara M, Mijatovic J, Vihavainen T, Piepponen TP, Saarma M, Ahtee L (2006) In heterozygous GDNF knockout mice the response of striatal dopaminergic system to acute morphine is altered. Synapse 59:321-329 